\title{
The N-Terminal Domain of Slack Determines the Formation and Trafficking of Slick/Slack Heteromeric Sodium- Activated Potassium Channels
}

\author{
Haijun Chen, ${ }^{1,2}$ Jack Kronengold, ${ }^{2}$ Yangyang Yan, ${ }^{3}$ Valeswara-Rao Gazula, ${ }^{2}$ Maile R. Brown, ${ }^{2}$ Liqun Ma, ${ }^{1}$ \\ Gonzalo Ferreira, ${ }^{4}$ Youshan Yang, ${ }^{3}$ Arin Bhattacharjee, ${ }^{5}$ Fred J. Sigworth, ${ }^{3}$ Larry Salkoff, ${ }^{6}$ and Leonard K. Kaczmarek ${ }^{2,3}$ \\ ${ }^{1}$ Department of Biological Sciences, State University of New York at Albany, Albany, New York 12222, Departments of ${ }^{2}$ Pharmacology and ${ }^{3}$ Molecular and \\ Cellular Physiology, Yale University School of Medicine, New Haven, Connecticut 06510, ${ }^{4}$ Department of Biophysics, School of Medicine, University of the \\ Republic, Montevideo 11800, Uruguay, ${ }^{5}$ Department of Pharmacology and Toxicology, State University of New York at Buffalo, Buffalo, New York 14214, \\ and ${ }^{6}$ Department of Anatomy and Neurobiology, Washington University School of Medicine, St. Louis, Missouri 63110
}

Potassium channels activated by intracellular $\mathrm{Na}^{+}$ions $\left(K_{\mathrm{Na}}\right)$ play several distinct roles in regulating the firing patterns of neurons, and, at the single channel level, their properties are quite diverse. Two known genes, Slick and Slack, encode $K_{\mathrm{Na}}$ channels. We have now found that Slick and Slack subunits coassemble to form heteromeric channels that differ from the homomers in their unitary conductance, kinetic behavior, subcellular localization, and response to activation of protein kinase $\mathrm{C}$. Heteromer formation requires the $\mathrm{N}$-terminal domain of Slack-B, one of the alternative splice variants of the Slack channel. This cytoplasmic N-terminal domain of Slack-B also facilitates the localization of heteromeric $K_{\mathrm{Na}}$ channels to the plasma membrane. Immunocytochemical studies indicate that Slick and Slack-B subunits are coexpressed in many central neurons. Our findings provide a molecular explanation for some of the diversity in reported properties of neuronal $K_{\mathrm{Na}}$ channels.

\section{Introduction}

Potassium channels allow potassium ions to cross cell membranes in response to physical and/or chemical stimuli such as changes in membrane potential or the binding of ligands. They play a key role in shaping the properties of excitable cells. A class of potassium channels reversibly activated by intracellular $\mathrm{Na}^{+}$ ions ( $K_{\mathrm{Na}}$ channels) were first described in inside-out patch recording of cardiac myocytes of guinea pig and were found to have high unitary $\mathrm{K}^{+}$conductance (Kameyama et al., 1984). Similar single $K_{\mathrm{Na}}$ channel activity was observed later in several types of neurons (Bader et al., 1985; Dryer et al., 1989; Egan et al., 1992a,b; Haimann et al., 1992; Koh et al., 1994; Safronov and Vogel, 1996; Bischoff et al., 1998; Hess et al., 2007) and other excitable and nonexcitable tissues (Rodrigo and Chapman, 1990; Wang et al., 1991; Niu and Meech, 2000; Paulais et al., 2006; Kim et al., 2007; Zhang and Paterson, 2007). A variety of studies have now shown that $K_{\mathrm{Na}}$ channels contribute to slow afterhyperpolarizations that

\footnotetext{
Received Dec. 16, 2008; revised April 2, 2009; accepted April 2, 2009.

This work was supported by American Heart Association (AHA) Scientist Development Grant $0635125 \mathrm{~N}$ (H.C.) and AHA and National Institutes of Health (NIH) Grants DC01919 (L.K.K.) and GM067154-01A1 and GM067154 (F.J.S. L.S.). We thank Drs. Hongmei Li and Elizabeth A. Jonas for technical advice. We thank Drs. Steve Goldstein and Dan Levy (University of Chicago, Chicago, IL) for pMAX vectors and valuable discussions. We thank Gonzalo Budelli and Alice Butler for their kind help. The mouse monoclonal anti-Slack antibody was developed by and obtained from the University of California Davis/National Institute of Neurological Disorders and Stroke/National Institute of Menta Health NeuroMab Facility, supported by NIH Grant U24NS05060.

Correspondence should be addressed to Leonard K. Kaczmarek, Department of Pharmacology, Yale University School of Medicine, New Haven, CT 06510. E-mail: leonard.kaczmarek@yale.edu. DOI:10.1523/JNEUROSCI.5978-08.2009

Copyright $\odot 2009$ Society for Neuroscience $\quad 0270-6474 / 09 / 295654-12 \$ 15.00 / 0$
}

follow bursts of action potentials in neurons (Safronov and Vogel, 1996; Yang et al., 2007).

Previous studies have documented diversities in the singlechannel properties of native $K_{\mathrm{Na}}$ channels (Dryer, 2003; Bhattacharjee and Kaczmarek, 2005). There are two known genes, Slick (Slo2.1) and Slack (Slo2.2), which encode $K_{\mathrm{Na}}$ channels (Joiner et al., 1998; Bhattacharjee et al., 2003; Yuan et al., 2003). There are several alternative isoforms of the Slack channel (Brown et al., 2008), and the first published Slack channel subunit (Joiner et al., 1998; Bhattacharjee et al., 2003; Yuan et al., 2003; Brown et al., 2008) is now termed Slack-B. Both Slick and Slack-B channels resemble native $K_{\mathrm{Na}}$ channels in their $\mathrm{Na}^{+}$sensitivity and large unitary conductances. The Slick channel differs from the Slack-B channel in that it is regulated by intracellular ATP through an ATP binding site in its $C$ terminus, and is more sensitive to internal $\mathrm{Cl}^{-}$ions than is Slack-B (Bhattacharjee et al., 2003). Immunocytochemical studies have demonstrated that Slick and Slack-B subunits are highly expressed in many regions of rat brain (Bhattacharjee et al., 2002, 2005), suggesting that they play important roles in regulating neuronal excitability. Slick or Slack-B can also be detected in other tissues such as heart and kidney at relatively lower levels. Interestingly, many neurons in the CNS express both Slick and Slack-B subunits (Bhattacharjee and Kaczmarek, 2005). In this study, we provide evidence that Slick and Slack-B form heteromeric $K_{\mathrm{Na}}$ channels in neurons and that the properties of these channels, particularly their modulation by protein kinase $C$, are quite distinct from those of homomeric channels. We also determined that the cytoplasmic N-terminal domain of Slack-B determines both the formation of Slick/Slack-B heteromeric $K_{\mathrm{Na}}$ 
A
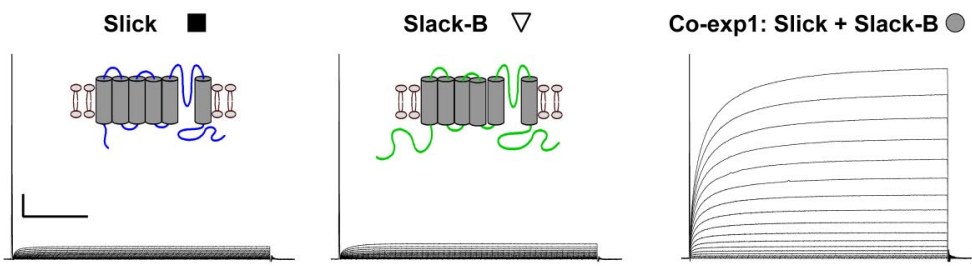

B

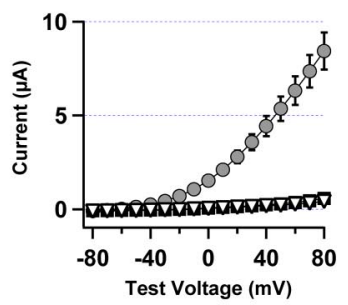

C

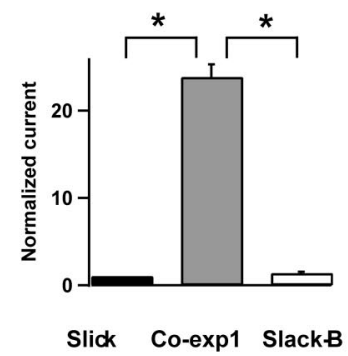

D

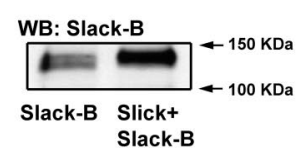

E
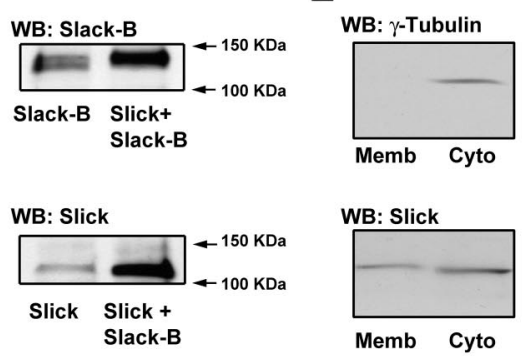

$\mathbf{F}$
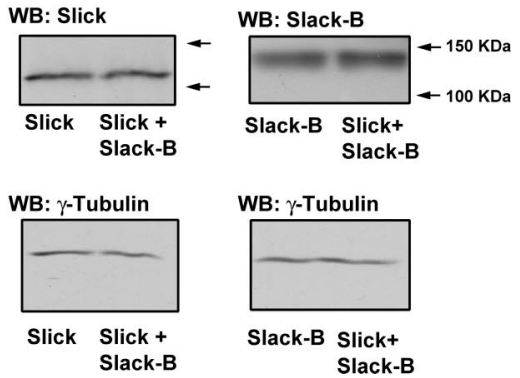

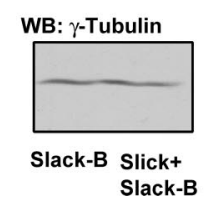

Figure 1. Coexpression of Slick and Slack-B dramatically increases whole-0ocyte currents compared with expression of either Slick or Slack-B alone. $A$, Representative families of whole-0ocyte currents evoked by stepping from -80 to $+80 \mathrm{mV}$ in $10 \mathrm{mV}$ increments in 0ocytes expressing Slick or Slack-B or coexpressing both subunits. Insets, Diagram for topology of Slick and Slack-B subunits. Calibration: $1 \mu \mathrm{A}, 100 \mathrm{~ms}$. B, Current-voltage relationship for oocytes expressing Slick or Slack-B or coexpressing both subunits. Currents were measured at the end of the test pulse. Symbols refer to those shown in $\boldsymbol{A}(\boldsymbol{N}=15-20)$. $\boldsymbol{C}$, Relative currents at $+60 \mathrm{mV}$ for the three groups of oocytes in $\boldsymbol{B}$. Currents were normalized to the value for Slick alone. ${ }^{*} p<0.001$. Error bars indicate SEM. D, Levels of surface expression of Slick and Slack-B subunits was evaluated by biotinylation and Western blotting analysis in three experimental conditions: expression of either subunit alone (left lanes) or coexpression of both Slick and Slack-B subunits at 1:1 ratio (right lanes) (membranes from 20 00cytes/per lane). Plasma membrane levels of both Slack-B (top) and Slick (bottom) were enhanced when coexpressed with the other subunit. $\boldsymbol{E}$, Membrane fractions prepared after biotinylation are negative for the cytoplasmic marker $\gamma$-tubulin. The membrane protein fraction was prepared from 5 oocytes injected with Slick cRNA and treated with biotinylation reagents as described in Materials and Methods. No immunoreactivity for the frog cytoplasmic protein $\gamma$-tubulin protein was detected (left lane, top). $\gamma$-Tubulin immunoreactivity was, however, found in the soluble cytoplasmic fraction (right lane, top). Slick immunoreactivity was detected in both plasma membrane and cytoplasmic fractions (bottom). $\boldsymbol{F}$, Total Slack-B or Slick protein levels are not significantly altered on coexpression with the other subunit. 0 ocytes were injected with cRNAs as described in the text. Five oocytes were lysed for each group and total protein samples for each group were obtained after centrifugation. Similar total levels of Slick were detected with expression of Slick alone or with coexpression with Slack-B (top left). Similarly, total Slack-B levels are not changed after coexpression with Slick (top right). The bottom panels show loading controls demonstrating similar levels of $\gamma$-tubulin in fractions from 0ocytes expressing Slick and Slack-B singly or in combination.

channels and their localization to the plasma membrane. Thus, heteromer formation between Slick and Slack-B requires a specific epitope that is found in the N-terminal domain of Slack-B and that is absent in the Slack-A isoform.

\section{Materials and Methods}

Molecular biology. In this study, rat Slick, Slack-A, and Slack-B cDNAs were used. For functional expression in Xenopus oocytes, Slack-B was cloned into pOX vectors (Yuan et al., 2003), and Slick or Slack-A were cloned into pOX or pMAX vectors (Rajan et al., 2005); green fluorescent protein (GFP) or red fluorescent protein (DsRed) were fused into the C-terminal of Slack-B, or Slack-A, or Slick, to clone Slack-B-GFP, SlackA-GFP, and Slick-DsRed into pMAX vectors; the Slick-EE mutant
(Q276E, Y279E) was made from Slick in pOX vectors by PCR mutagenesis; the chimera of Slick and Slack-B was first created in pcDNA3 (Invitrogen), by replacing the Slick $\mathrm{N}$ terminus (63 aa residues) with the Slack-B $\mathrm{N}$ terminus (96 aa residues), and then the whole modified gene was cloned into pMAX vectors. The construction of stably transfected HEK293 cells was as follows: Slack-B-Flag, a Flag tag was linked to the $\mathrm{C}$ terminus of Slack-B, and then the whole gene was inserted in pcDNA3 vector; GFPSlack-B-Flag, Slack-B gene with both GFP and Flag tags in the $\mathrm{N}$ - and C-terminal, respectively, was cloned into the pEGFP-C1 vector (Clontech); DsRed-Slick, Slick with DsRed was cloned into pDSRed-Monomer-C1 vectors (Clontech). Independent constructs were made with DsRed either at the $\mathrm{N}$ or $\mathrm{C}$ terminus; 3XFlag-Slick, Slick was constructed in pCMV-3Tag-1A vector (Stratagene); Slick-hemagglutinin (HA), an HA tag was linked into the $\mathrm{C}$ terminus of Slick and the fusion construct was cloned into pMAX vectors. Selection of each of these stably transfected cell lines, as well as cotransfected cells, was performed using G418 sulfate (Invitrogen). All cDNAs were confirmed by sequencing and restriction digestions.

Coimmunoprecipitation of Slick and Slack subunits in vitro and in vivo. HEK293 cells were cultured in modified DMEM media until at least $80 \%$ confluence, and then cotransfected with DsRed-Slick and Slack-B-Flag or GFPSlack-B-Flag constructs. As controls, separate transfections with either DsRed-Slick alone or Slack-B-Flag alone (or GFP-Slack-B-Flag alone) were done in parallel. G418 sulfate (Invitrogen) at $600 \mu \mathrm{g} / \mathrm{ml}$ was used to maintain stably transfected HEK293 cells for at least 8 weeks, and maintenance of expression was confirmed by examination of fluorescent signals. Cells stably expressing both DsRed-Slick and Slack-B-Flag (or GFP-Slack-B-Flag) subunits were homogenized with a storage buffer containing the following (in $\mathrm{mm}$ ): 10 Tris- $\mathrm{HCl}, 5$ $\mathrm{KCl}, 1 \mathrm{MgCl}_{2}, 1 \mathrm{EGTA}$, and protease inhibitor mixture (PI) (1:100 dilution; Sigma-Aldrich), $\mathrm{pH}$ 7.4. After centrifugation at $1000 \times g$, the membrane fraction was prepared by subsequent centrifugation at $14,000 \times g$. The extracted membrane proteins were solubilized in a buffer containing the following (in $\mathrm{mm}$ ): 100 $\mathrm{KCl}, 50 \mathrm{NaCl}, 50$ Tris-HCl, 5 EDTA, 16 DDM (dodecyl maltoside) (Calbiochem), and PI, pH 7.4. The channels or channel complexes were pulled down with M2-anti-Flag agarose beads (Sigma-Aldrich) and eluted by Flag peptide (Sigma-Aldrich). The eluted proteins were incubated in the urea sample buffer, run on a $6 \%$ SDSPAGE gel, and transferred to a PVDF (polyvinylidene difluoride) membrane. The membrane was probed with the anti-DsRed polyclonal antibody (Clontech) and anti-Flag M2 antibody (Sigma-Aldrich). Similarly, the stable transfections were completed for Slack-A-HA alone or both DsRed-Slick and Slack-A-HA plasmids, respectively. Anti-HA agarose beads (Sigma-Aldrich) were used to immunoprecipitate channels or channel complexes, and high-affinity anti-HA antibody (Roche) was used for Western blotting analysis.

Brainstems and olfactory bulbs from six rat brains were homogenized and briefly sonicated in a cold buffer containing the following (in $\mathrm{mm}$ ): $50 \mathrm{NaCl}, 50 \mathrm{KCl}$, and 50 Tris- $\mathrm{HCl}, \mathrm{pH}$ 7.4. The membrane fractions were 
isolated, and protein samples were solubilized in the same buffer containing $1 \%$ Triton X-100. Coimmunoprecipitation of Slick and Slack-B from brain tissues was done with the ProFound Coimmunoprecipitation kit (Pierce). Briefly, chicken anti-Slack-B antibodies were coupled onto agarose beads on a column. After incubation, the extracted membrane protein samples were passed through this column, and the channels or channel complexes containing Slack-B subunits were eluted. Slick and Slack proteins were detected by standard Western blotting analysis.

Immunocytochemistry. Detailed procedures have been described previously (Santi et al., 2006). Briefly, adult rats were anesthetized with sodium pentobarbital and perfused through the left ventricle with PBS solutions. Brains were removed, postfixed in $4 \%$ paraformaldehyde overnight at $4^{\circ} \mathrm{C}$, and sliced sagittally on a vibratome (Leica VT1000S) at $20 \mu \mathrm{m}$. After the postfixed and permeabilized preparation, freefloating slice sections were processed for double labeling with chicken anti-Slick $(1.5 \mu \mathrm{g} / \mathrm{ml})$ and mouse anti-Slack $(2.6 \mu \mathrm{g} / \mathrm{ml}$; NeuroMab). After $48 \mathrm{~h}$ of incubation at $4^{\circ} \mathrm{C}$ in primary antibody, sections were washed three times for 10 min each. Fluorescent secondary antibodies were used to identify the double labeling: mouse Alexa 488 (Invitrogen) for Slack staining and chicken Cy3 (Jackson ImmunoResearch) for Slick staining. In the negative control experiments, sections were processed through the same procedure without primary or secondary antibody.

Image acquisition and analysis. For examination of the localization of Slack-B-GFP and Slick-DsRed in HEK293 cells, the stably transfected cells were plated on coverslips, fixed with $3 \%$ formaldehyde, and covered by mounting medium (H-1000; Vector Laboratories). Pictures were taken on a Zeiss Micro System LSM confocal microscope with excitation of 488 and 568, emission of 515-565 and 590-640 for GFP and DsRed, respectively. Line scans of pixel intensity across cells were obtained using Image J software.

Images from both brain slices and Xenopus oocytes were taken with a Zeiss laser-scanning microscope (LSM META150) coupled to a computer with Zeiss image acquisition and analysis software. We used Adobe Photoshop to sharpen images, adjust brightness and contrast level, and compose final plates. For live images of Xenopus oocytes expressing Slick and/or Slack subunits with fluorescent tags, we took the images at the focal plane of the maximal circumference of the oocytes, which were incubated in the ND96 solution.

Electrophysiology. Oocytes isolated from Xenopus laevis frogs were defolliculated by collagenase treatment and injected with $46 \mathrm{nl}$ of sterile water containing $\sim 10 \mathrm{ng}$ of cRNA (Slick or Slack alone, or mixture of Slick and Slack with 1:1 ratio), unless otherwise noted, and studied $5 \mathrm{~d}$ thereafter. cRNA was made with mMessage mMachine RNA kits (Ambion). Whole-oocyte currents were measured by a two-electrode voltage clamp amplifier (Warner Instruments). Electrodes were filled with $3 \mathrm{M}$ $\mathrm{KCl}$ and had resistance $0.1-1.2 \mathrm{M} \Omega$. Data were sampled at $1 \mathrm{kHz}$ and filtered at $0.25 \mathrm{kHz}$. Standard bath solution was ND96 containing the following (in mM): $96 \mathrm{NaCl}, 2 \mathrm{KCl}, 1 \mathrm{MgCl}_{2}, 1.8 \mathrm{CaCl}_{2}, 5 \mathrm{HEPES} / \mathrm{NaOH}$,

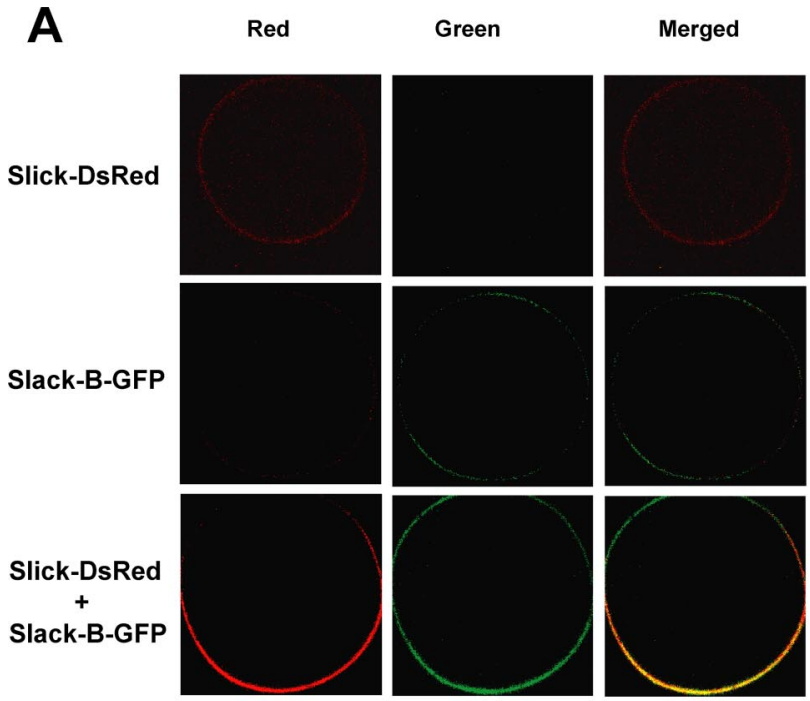

B Analysis
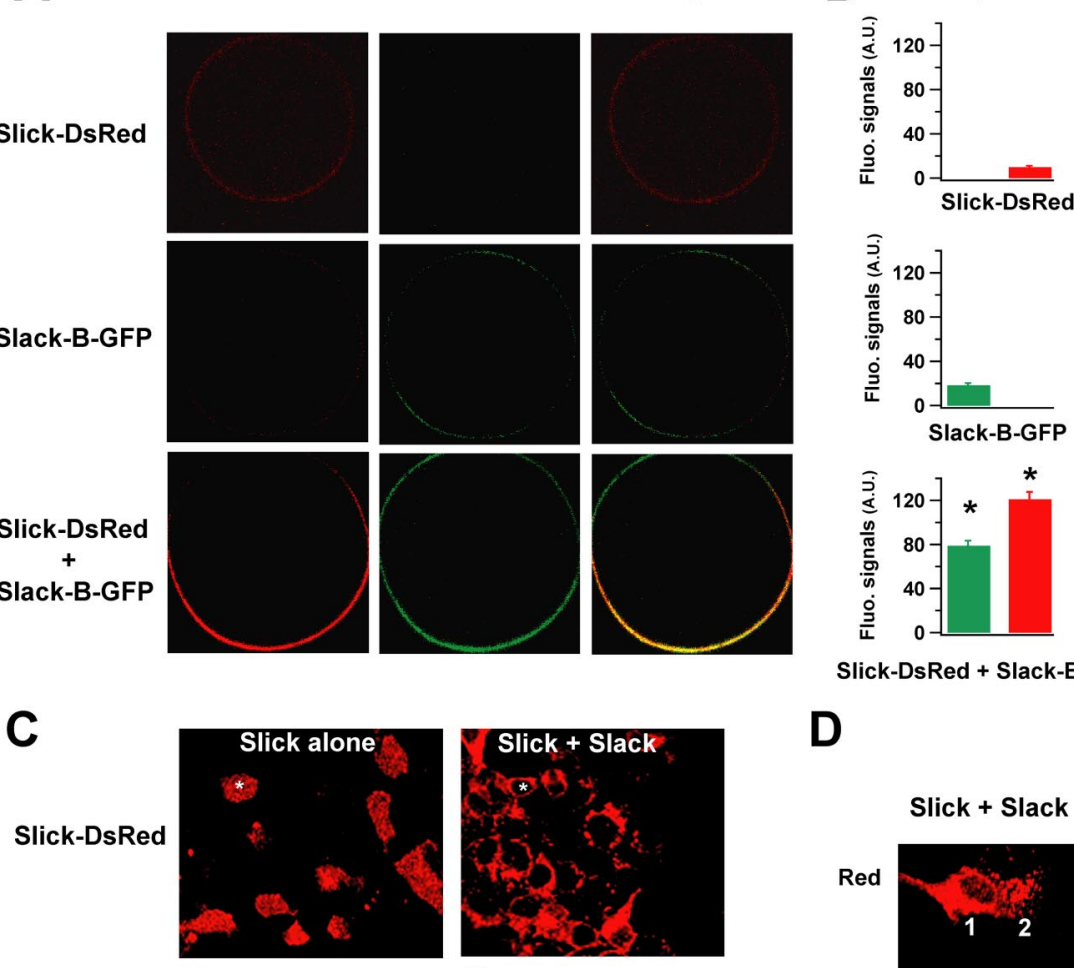

Slick-DsRed + Slack-B-GFP

D
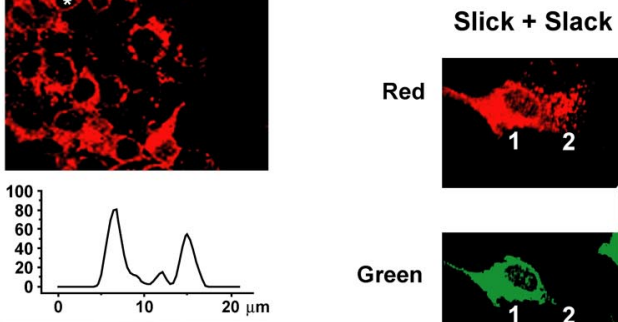

Green
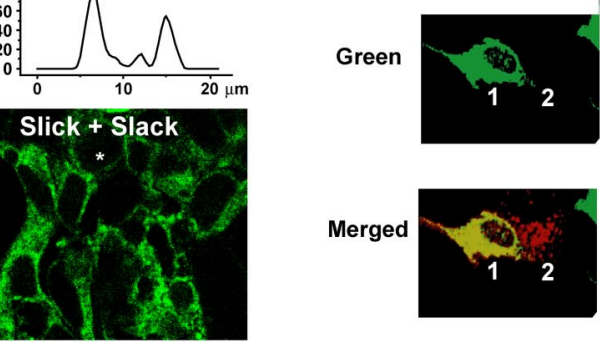

Figure 2. Coexpression of Slick and Slack-B increases localization of heteromeric channels to the plasma membrane. $A$, Confocal images of homomeric Slick (top row) or Slack-B channels (middle row) and heteromeric Slick/Slack-B channels (bottom row) expressed in Xenopus 0ocytes. Fusion constructs Slick-DsRed and Slack-B-GFP were used. B, Bar graphs in the "Analysis" column show the relative levels of fluorescence at the animal pole of the ooctyes ( ${ }^{*} p<0.0001$ for red or green signals). In the bottom row of images (Slick/Slack coinjected), the oocyte animal pole orients downward, and the major population of channels expressed in the plasma membrane are likely to represent heteromeric Slick/Slack-B channels, although there may be a small fraction of homomeric Slick and/or Slack-B channels. Error bars indicate SEM. C, Patterns of distribution of fluorescence in HEK293 cells stably expressing either Slick-DsRed or Slack-B-GFP alone (left panels, top and bottom, respectively) or coexpressing both subunits (right panels). Line scans below each image show levels of pixel intensity in line scans across the diameter of the representative cells identified by white asterisks on the images. D, A comparison of the distribution of fluorescence in a HEK293 cell coexpressing both Slick-DsRed and Slack-B-GFP subunits (cell 1) located adjacent to a cell expressing Slick-DsRed alone (cell 2).

$\mathrm{pH}$ 7.5. For measurement of channel activation, oocytes were depolarized by $400 \mathrm{~ms}$ pulses from a holding potential of $-90 \mathrm{mV}$ to test voltages between -80 and $+80 \mathrm{mV}$ in $10 \mathrm{mV}$ increments every $5 \mathrm{~s}$. For patchclamp recording, injected Xenopus oocytes were manually devitellinized in a hypertonic solution containing the following (in $\mathrm{mM}$ ): $220 \mathrm{Na}$ aspartate, $10 \mathrm{KCl}, 2 \mathrm{MgCl}_{2}, 10 \mathrm{HEPES}$, and then incubated in the ND96 solution without $\mathrm{Ca}^{2+}$ for recovery. Internal patch pipette solutions contained the following (in $\mathrm{mm}$ ): $140 \mathrm{KCl}, 5 \mathrm{NaCl}, 5 \mathrm{EGTA}, 1 \mathrm{CaCl}_{2}, 1$ $\mathrm{MgCl}_{2}, 5 \mathrm{HEPES} / \mathrm{KOH}, \mathrm{pH}$ 7.5. Cell-attached and excised inside-out patch recordings were performed using symmetrical $140 \mathrm{KCl}$ solutions. Single-channel currents in Xenopus oocytes were recorded using an Axopatch 1D amplifier (Molecular Devices). Currents were filtered at $1 \mathrm{kHz}$ 
A
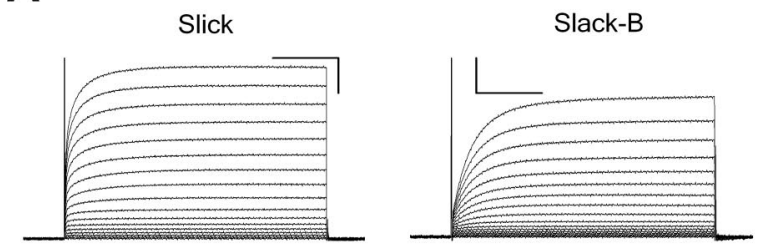

Co-exp1: Slick + Slack-B

B
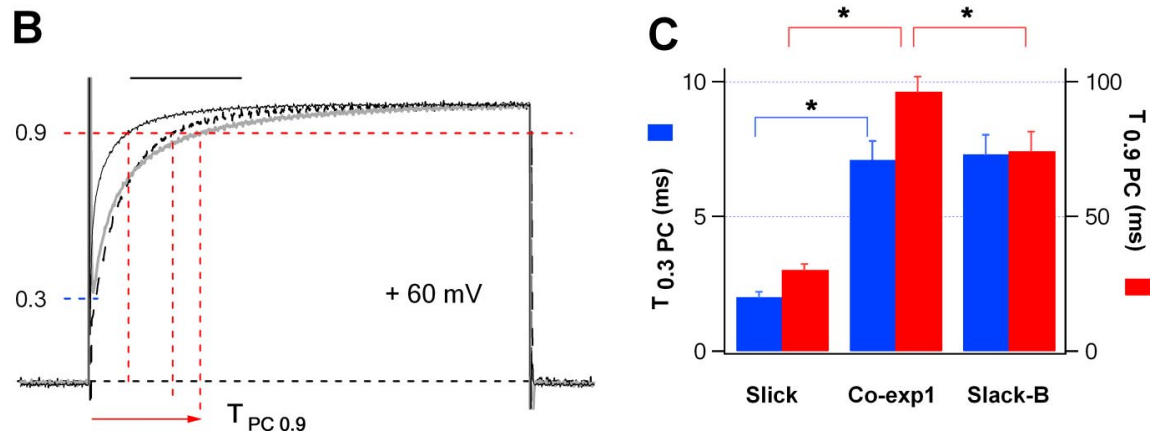

Figure 3. Activation kinetics of homomeric Slick or Slack-B channels and heteromeric Slick/Slack-B channels. $A$, Representative families of whole-0ocyte currents for three types of channels. Calibration: $1 \mu \mathrm{A}, 100 \mathrm{~ms}$. A total of $70 \mathrm{ng}$ of cRNA was injected into oocytes to produce comparable whole-0ocyte currents of homomeric Slick or Slack-B channels, whereas $10 \mathrm{ng}$ of cRNA of Slick and Slack-B with 1:1 ratio was used to express heteromeric Slick/Slack-B channels. $B$, Normalized currents at $+60 \mathrm{mV}$ for three types of channels (Slick, solid line; Slack-B, dashed line; heteromeric Slick/Slack-B, gray line). Calibration: 100 ms. C, Activation time to $30 \%$ (blue) and $90 \%$ (red) peak currents at $+60 \mathrm{mV}^{*} p<0.001 ; n=12-30$. Error bars indicate SEM.

and data were acquired at $10 \mathrm{kHz}$. Data recording and analysis were performed using pClamp (Molecular Devices), Excel (Microsoft), Origin 6.0 (MicroSoft), and IGOR (Wavemetrics) software packages.

Surface biotinylation in Xenopus oocytes. Five days after cRNA injection, oocytes were incubated in $0.5 \mathrm{mg} / \mathrm{ml} \mathrm{EZ-Link} \mathrm{Sulfo-SS-Biotin}$ (Pierce) in ND96 for $30 \mathrm{~min}$. Twenty oocytes for each group were homogenized and lysed in PBS containing 1\% Triton X-100 and protease inhibitors. The samples were centrifuged at $1000 \times g$ at $4^{\circ} \mathrm{C}$ for $5 \mathrm{~min}$ to remove yolk, and the supernatant was added to $50 \mu \mathrm{l}$ of immobilized streptavidin beaded agarose (Pierce), incubated overnight at $4^{\circ} \mathrm{C}$, and extensively washed. The proteins expressed in the plasma membrane of oocytes were pulled down with streptavidin beads, and eluted with sample buffer containing $200 \mathrm{~mm}$ DTT. The protein samples were analyzed by Western blotting with chicken anti-Slick and anti-Slack-B (Bhattacharjee et al., 2002, 2005). For Western blotting, a monoclonal anti- $\gamma$ tubulin antibody (Sigma-Aldrich) was also used as a loading control.

\section{Results}

\section{Coexpression of Slick and Slack-B enhances expression of} channels in the plasma membrane

For potassium channel subunits that form heteromeric complexes in vivo, it has typically been found that, when the two subunits are coexpressed in a heterologous system, the level of whole-cell current is substantially enhanced over that produced by either subunit alone. This is the case, for example, for heteromeric KCNQ2 and KCNQ3 (Wang et al., 1998; Schwake et al., 2000) and heteromeric inward rectifier channels formed from Kir family subunits (Pessia et al., 1996; Hofherr et al., 2005). To determine whether Slick and Slack-B may coassemble to form functional channels, we therefore first injected Xenopus oocytes with cRNA for these two subunits at a 1:1 ratio and studied properties of expressed channels. Coexpression of Slick and Slack-B resulted in a large increase in whole-oocyte currents compared with expression of the same amount of total cRNA for either subunit alone (Fig. $1 A-C$ ). Coexpression of Slick and Slack-B increased whole-oocyte currents at $+60 \mathrm{mV}$ by 25 -fold and 18 fold, respectively, compared with expression of Slick or Slack-B alone. A similar increase in whole-cell current was also observed when Slack-B and Slick were coexpressed in mammalian HEK293 cells, compared with expression of either subunit alone $(N=14)$ (data not shown). These results strongly suggest that Slick and Slack-B form heteromeric channels.

Although we cannot exclude the possibility that changes in open probability and unitary conductance contribute to the increase of whole-cell currents, the magnitude of the increase in current suggests that the formation of heteromeric Slick/ Slack-B channels results in an increase in the number of functional channels in the plasma membrane. We therefore next determined the levels of surface expression of Slick and Slack-B subunits using a surface biotinylation assay. Consistent with the whole-oocyte recordings, levels of Slick and Slack-B proteins in the plasma membrane of Xenopus oocytes were increased when both subunits were coexpressed at a 1:1 ratio, compared with expression of either subunit alone (Fig. 1D). To control for the integrity of the plasma membrane during biotinylation, we tested for the presence of the cytoplasmic protein $\gamma$-tubulin in the biotinylated fraction. No $\gamma$-tubulin immunoreactivity could be found in this fraction, but was readily detected in the cytoplasmic fraction from the same oocytes (Fig. $1 E$ ). We also performed control experiments in oocytes injected with cRNAs for Slick or for both subunits in which we omitted the biotinylation step but performed all of the subsequent steps as for preparation of the plasma membrane fraction. No Slick immunoreactivity was detected in the fraction from these negative control experiments (data not shown).

Although plasma membrane levels of Slick and Slack-B were enhanced after coexpression, no difference in total oocyte protein levels of either protein was found when these subunits were expressed singly or in combination with the other subunit (Fig. $1 F$ ). These results indicate that the localization of heteromeric Slick/ Slack-B channels to the plasma membrane is enhanced over that of homomeric Slick or Slack channels.

We also used a second strategy to examine the formation of heteromeric Slick/Slack-B channels and their distribution in the membrane of Xenopus oocytes. We made two fusion constructs, Slack-B-GFP and Slick-DsRed, which introduced the fluorescent tags GFP and DsRed, into the C termini of the Slack-B and Slick subunits, respectively. When coexpressed in Xenopus oocytes, strong overlapping red and green signals were detected at the surface of the oocytes. Interestingly, both red and green signals were polarized to the animal pole of the oocytes (Fig. $2 A$ ). In contrast, when either Slick-DsRed or Slack-B-GFP was expressed alone in oocytes, the red signal and green signals were very weak (Fig. 2A,B).

To examine in more detail the subcellular localization of Slack and Slick subunits, we used transfected HEK293 cells stably expressing Slack-B-GFP and Slick-DsRed, either alone or in combination. The use of these mammalian cells allows visualization of the relative distribution of subunits between internal membranes and those at the periphery or surface of cells. In cells 


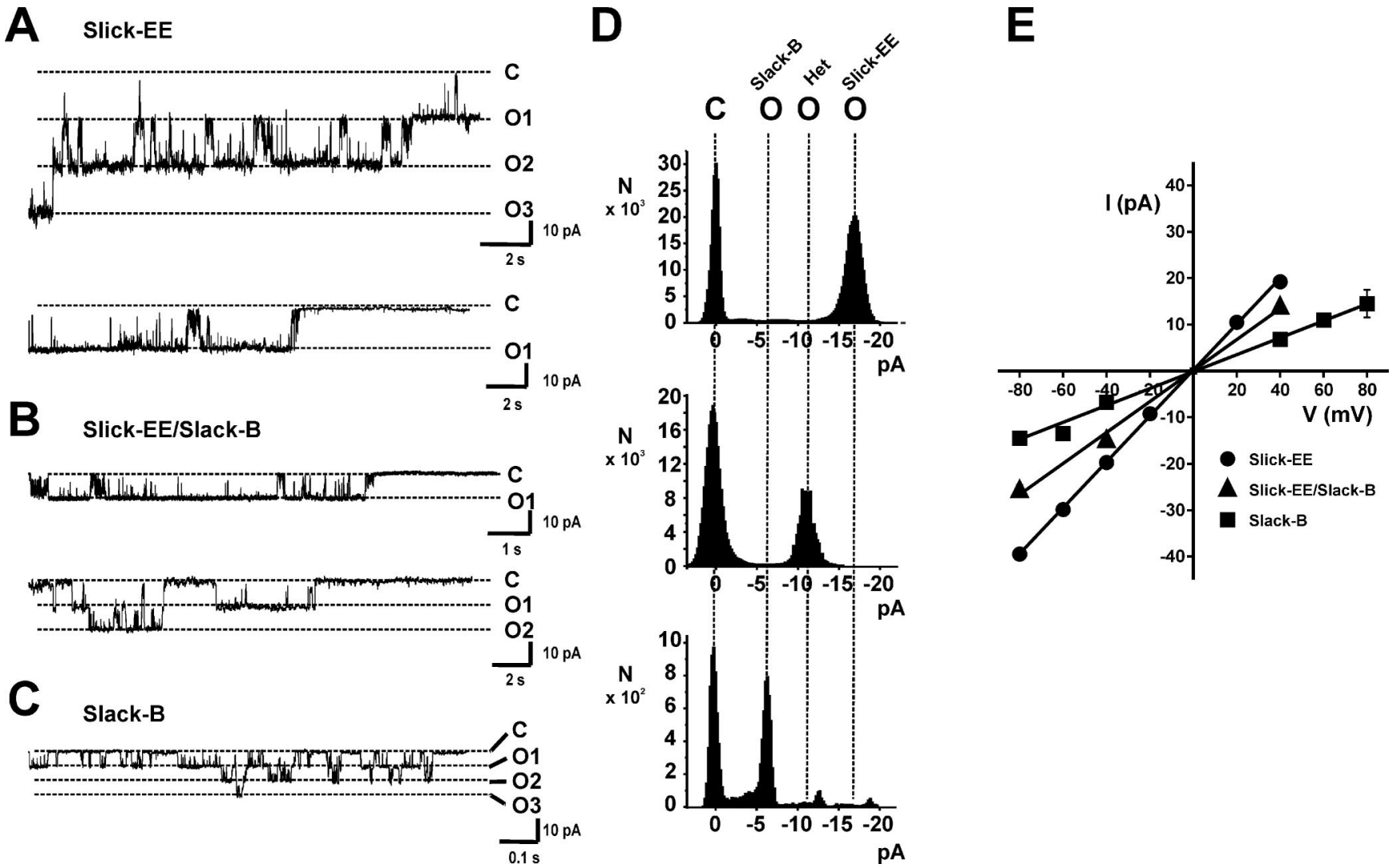

Figure 4. Unitary conductance of heteromeric Slick-EE/Slack-B channels is distinct from that of homomeric Slick-EE or Slack-B channels. $A-C$, Representative single-channel activities recorded from oocytes expressing Slick-EE alone $(\boldsymbol{A})$ or coinjected with equal amounts of cRNA for Slick-EE and Slack B $(\boldsymbol{B})$, or expressing Slack-B alone $(\boldsymbol{C})$. All current traces were recorded at $-40 \mathrm{mV}$ from excised inside-out patches. The top and bottom traces in $A$ and $B$ are from separate experiments. The closed state $(C)$ and openings levels corresponding to one to three open channels (01-03) are shown. $\boldsymbol{D}$, All points amplitude histograms are shown for $(\boldsymbol{A}$, top; $\boldsymbol{B}$, center; $\boldsymbol{C}$, bottom). The vertical lines align closed states $(\boldsymbol{C})$ and single open states $(0)$ for homomeric Slack-B channels, heteromeric channels (Het), and homomeric Slick-EE channels. E, Unitary current-voltage relationships for homomeric Slick-EE channels ( $\sim 495$ pS), Slack-B channels ( 180 pS), and heteromeric Slick-EE/ Slack-B channels ( $\sim 324$ pS).

expressing Slick-DsRed alone, the majority of the Slick-DsRed signal was localized to discrete puncta within the cytoplasm of the cells (Fig. 2C). Although line scans of pixel intensity across the center of Slack-DsRed-expressing cells sometimes revealed a slight elevation of fluorescence at the edge of a cell (Fig. 2C, top left), in no cell could a clear ring of peripheral staining be detected (three plates of cells). In contrast, on coexpression of both subunits, a different distribution of Slick-DsRed was observed, with the majority of the red signal at the periphery of the cells (Fig. $2 C)$. In line scans across the cells, clear peaks of Slick-DsRed fluorescence could be detected at the edge of the cells (Fig. 2C, top right). Compared with cells expressing Slick-DsRed alone, $86 \pm$ $2 \%$ of cotransfected cells had a clear ring of peripheral staining ( $p<0.0001$; eight fields of images, 10-76 cells each). This difference in subcellular localization was particularly evident on comparing the distribution of fluorescence in a cell coexpressing both subunits located adjacent to a cell expressing Slick-DsRed alone (Fig. 2D). A similar difference in distribution of Slack-BGFP was found in cells expressing this subunit alone or with the Slick-construct. Although peripheral staining consistent with localization to the plasma membrane, as well as internal staining, could clearly be detected in images and line scans of cells expressing Slack-B-GFP alone, the degree of peripheral localization was significantly enhanced in cells expressing both subunits (Fig. 2C). In cells expressing Slack-B-GFP alone, only $13 \pm 6 \%$ of cells had predominantly peripheral Slack-B-GFP staining (four fields of images, $8-64$ cells each), whereas this value was $83 \pm 3 \%$ for cotransfected cells (eight fields of images, 5-58 cells each) $(p<$ $0.0001)$. These observations on oocytes and HEK293 cells are consistent with the above findings using whole-oocyte voltageclamp recording and surface biotinylation analysis, and support the hypothesis that Slick and Slack-B form heteromeric channel complexes and that heteromer formation enhances trafficking to the plasma membrane, or stabilizes their presence in the plasma membrane.

Macroscopic currents of heteromeric Slick/Slack-B channels differ from those of homomeric channels

Homomeric Slick and Slack-B channels differ from each other in a number of biophysical properties including their activation kinetics. Slick channels activate rapidly on depolarization, whereas activation of Slack-B channels is biphasic with a voltagedependent component that activates slowly over hundreds of milliseconds (Bhattacharjee et al., 2003). To compare the activation kinetics of heteromeric Slick/Slack-B channels with those of homomeric Slick or Slack-B channels, we injected Xenopus oocytes with amounts of cRNA for either subunit alone or for both together that give rise to similar levels of expressed current in the oocytes (Fig. $3 A$ ). To quantify activation, we measured the time for current amplitudes to reach either 30 or $90 \%$ of their steadystate values at $+60 \mathrm{mV}$. Slick currents activate significantly faster than either Slack-B or Slick/Slack-B currents. Moreover, there was no difference between time to reach $30 \%$ activation between Slack-B homomers and Slick/Slack-B currents. In contrast, the 


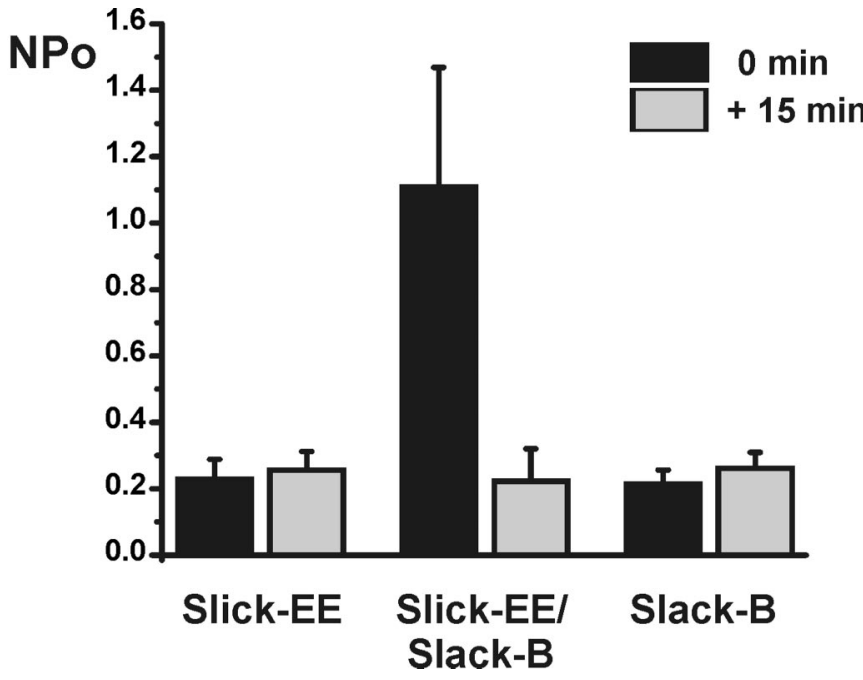

Figure 5. Heteromeric Slick/Slack-B channels rundown after patch excision. Changes in NP0 were measured immediately after excision into symmetric $140 \mathrm{~mm} \mathrm{~K}^{+}$solutions for patches from 0ocytes expressing Slick-EE alone, coinjected with equal amounts of CRNA for Slick-EE and Slack $B$, or expressing Slack-B alone. Currents were recorded at $-80 \mathrm{mV} . N=7,6,5$ for Slick-EE, Slack-B/Slick-EE, and Slack-B, respectively. Error bars indicate SEM.

A

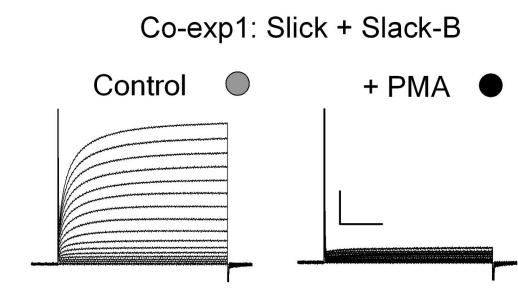

B

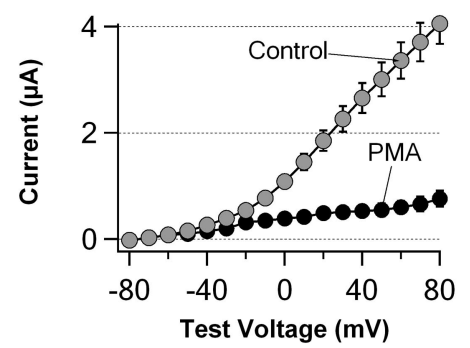

\section{C}

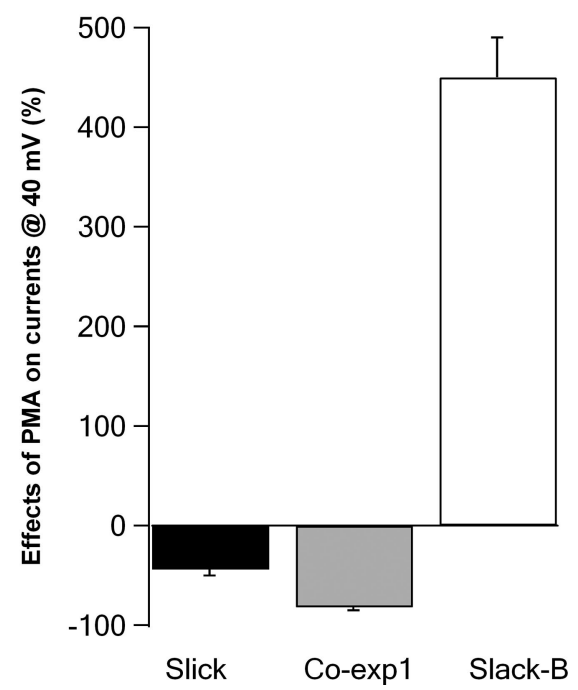

Figure 6. Effects of protein kinase C activator PMA on heteromeric Slick/Slack-B channels. $\boldsymbol{A}$, Representative families of whole-00cyte currents of heteromeric Slick/Slack-B channels before and after application $100 \mathrm{~nm}$ PMA. Calibration: $1 \mu \mathrm{A}, 100 \mathrm{~ms}$. $\boldsymbol{B}$, Current-voltage relationships for $\boldsymbol{A}$. C, Comparison of effects of PMA on currents at $40 \mathrm{mV}$ of three types of channels: homomeric Slick channels, heteromeric Slick/Slack-B channels, and homomeric Slack-B channels $(N=10)$. Error bars indicate SEM.

obtained by comparing the unitary conductance of the expressed channels. Wild-type Slick channels have a single channel conductance of $\sim 140 \mathrm{pS}$ in symmetrical $\mathrm{K}^{+}$solutions $\left(130 \mathrm{mM} \mathrm{K}^{+}\right)$, whereas Slack channels have a slightly higher conductance $(\sim 180$ pS) under the same recording conditions. Heteromeric Slick/ Slack-B channels are therefore likely to have a unitary conductance between these two values. The fact that the Slick and Slack-B conductances are close in value could, however, make it to difficult to discern such an intermediate conductance definitively.

To circumvent this problem, we made a pore mutant of the Slick channel, Slick-EE (Q276E, Y279E), that greatly increases its unitary conductance. The design of this mutant was based on findings that similar mutations in amino acids corresponding to these positions in BK and KcsA channels increase their unitary conductance (Brelidze et al., 2003; Nimigean et al., 2003). Xenopus oocytes were injected with cRNA for Slick-EE and channel activity was characterized in cell-attached and excised inside-out patch recordings from these oocytes. We found that, in contrast to wild-type Slick channels, which have a unitary conductance of $140 \mathrm{pS}$, the single channel conductance of Slick-EE is $495 \pm 6 \mathrm{pS}$ $(N=7)$ in symmetric $140 \mathrm{~mm} \mathrm{~K}^{+}$solutions (Fig. $\left.4 A, D, E\right)$. This correlates well with macroscopic currents obtained by injection of equal amounts $(75$ ng) of either Slick or Slick-EE RNA in oocytes, for which the Slick-EE mutant shows fourfold to fivefold larger currents (data not shown). Under the same conditions, channels excised from Slack-B-expressing oocytes had a unitary conductance of $182 \pm 16 \mathrm{pS}(N=3)$ (Fig. $4 C-E)$ (Bhattacharjee et al., 2003).

When ooctyes were coinjected with Slick-EE and Slack-B, the dominant channels in excised patches had a unitary conductance of $324 \pm 8 \mathrm{pS}(N=8)$, which is intermediate between that of homomers of Slick-EE and Slack-B and is clearly distinct from that for either channel alone (Fig. $4 A, C-E)$. These findings provide definitive electrophysiological evidence for the formation of heteromeric channels in Slick/Slack-B-coinjected cells.

Heteromeric Slick/Slack-B channels, like native $K_{\mathrm{Na}}$ channels, are subject to rundown after patch excision

Recording of unitary $K_{\mathrm{Na}}$ channels from neurons of the olfactory bulb, in which

time for the Slick/Slack-B currents to reach $90 \%$ activation was significantly longer than that for either Slick or Slack-B homomeric currents (Fig. $3 B, C$ ). This finding implies that the macroscopic time course of Slick/Slack-B currents cannot be accounted for by any linear summation of Slick and Slack-B homomeric currents, and supports the hypothesis that currents in Slick/ Slack-B-coinjected cells represent heteromeric Slick/Slack-B channels that have kinetic properties distinct from those of the homomeric channels.

Biophysical properties of heteromeric Slick/Slack-B channels are distinct from those of homomeric channels

More direct electrophysiological evidence for the formation of heteromeric channels in Slick/Slack-B-coexpressing oocytes was both Slack-B and Slick are coexpressed at high levels (Bhattacharjee et al., 2002, 2005), have found that these channels undergo rundown over a period of many minutes after excision of the patch from the plasma membrane (Egan et al., 1992a). In contrast, no rundown is observed in cell-attached patches, suggesting that these channels are sensitive to an intracellular factor that is lost after excision of the patch. Rundown after excision is not observed for $K_{\mathrm{Na}}$ channels in all cell types, suggesting that such regulation by an intracellular factor may depend on the types of $K_{\mathrm{Na}}$ channels expressed. We therefore compared channel rundown for Slack-B, Slick-EE, and Slack-B/Slick-EE heteromeric channels expressed in Xenopus oocytes at different times after patch excision into symmetric $140 \mathrm{~mm} \mathrm{~K}{ }^{+}$solutions. We quantified changes in NPo (number of channels $X$ probability of 


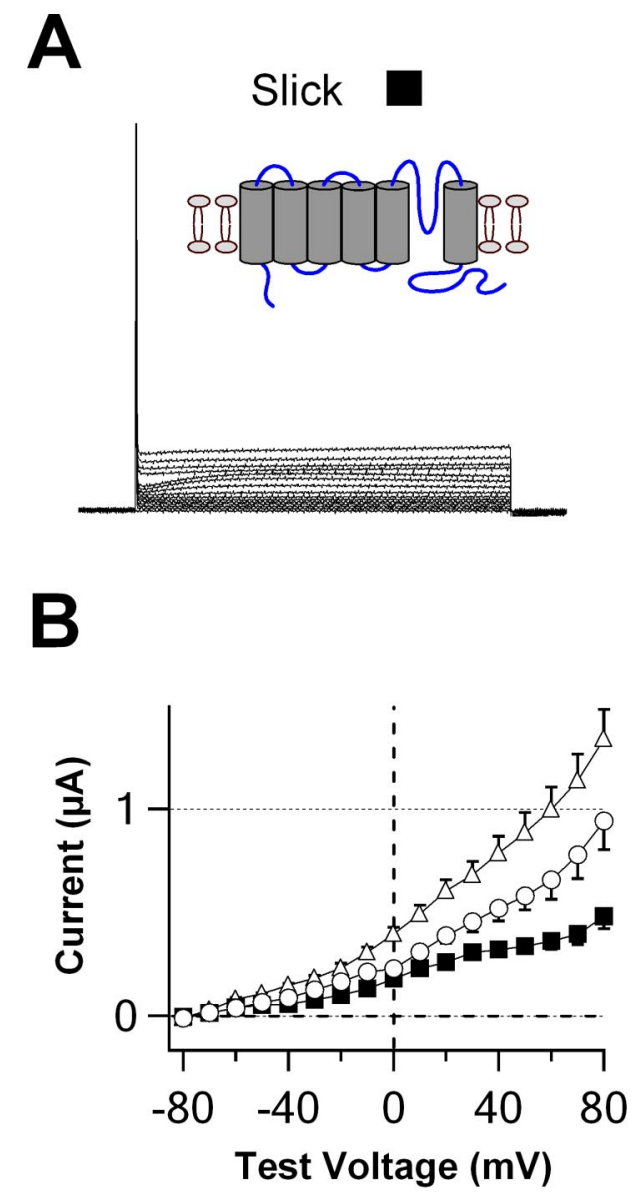

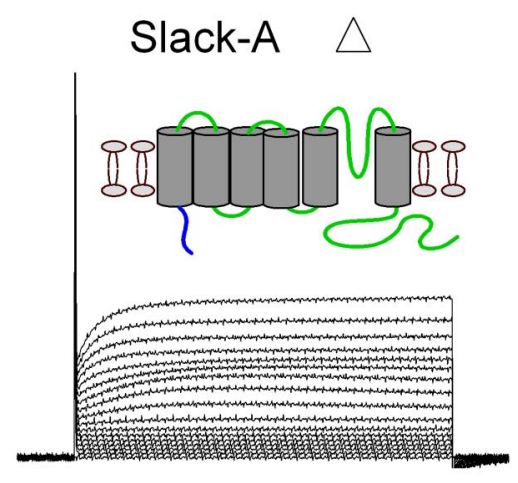

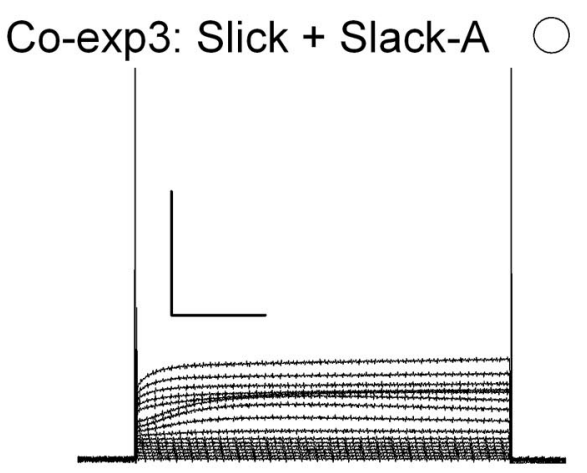

C

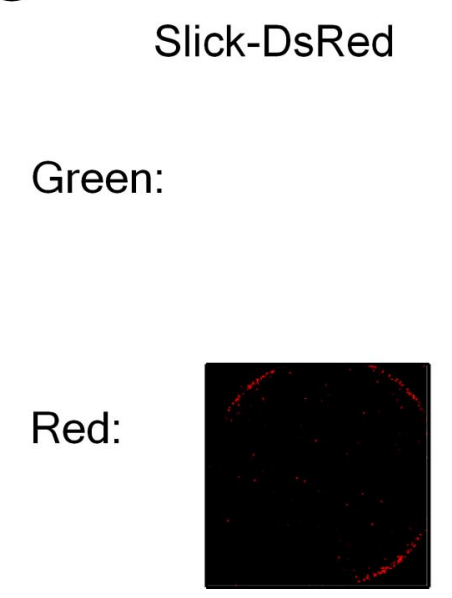

Slack-A-GFP
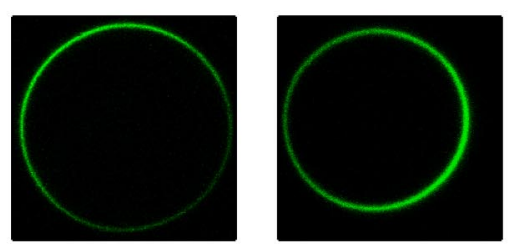

Figure 7. Slick subunits do not form channel complexes with Slack-A subunits. $A$, Representative families of whole-0ocyte currents for three experimental conditions: coexpression of Slick and Slack-A or expression of either Slick or Slack-A alone. Coexpression of Slick and Slack-A did not increase whole-0ocyte currents, unlike coexpression of Slick and Slack-B. Apparent discontinuities in activation kinetics in traces for Slick coexpression of either Slick or Slack-A were typically only observed with low levels of expression and may result from some contamination by endogenous components. Insets, Schematics of topology for Slick and Slack-A subunits. Calibration: $1 \mu \mathrm{A}, 100 \mathrm{~ms}$. B, Current-voltage relationships for these three conditions ( $N=11$ ). Error bars indicate SEM. C, Confocal images of Xenopus oocytes expressing both Slick-DsRed and Slack-A-GFP subunits or either subunits alone.

opening) immediately after excision and 15 min after excision. For the homomeric Slack-B or Slick-EE channels, no change in NPo was detected over this time ( $N=5,7$, respectively) (Fig. 5). In contrast, the activity of heteromeric Slick-EE/Slack-B channels was reduced to $\sim 20 \%$ of its initial value over $15 \mathrm{~min}(N=6)$ (Fig. 5 ). With longer times after excision, however, generally little or no additional rundown occurred, and in no case was channel activity lost altogether. These findings suggest that Slick/Slack-B heteromers, in common with native $K_{\mathrm{Na}}$ channels in olfactory neurons, are sensitive to an, as-yet-uncharacterized, intracellular factor, and that the homomeric channels are less sensitive to this factor.

Regulation of Slick/Slack-B channels by protein kinase C differs from that of homomeric channels

Previous studies have shown that Slick and Slack-B channels are potently regulated in opposite directions by activation of protein kinase C (PKC) (Santi et al., 2006). Treatment of Slack-Bexpressing cells with PKC activators increases the amplitude of homomeric Slack-B currents severalfold and slows their rate of activation. In contrast, activation of PKC reduces currents in cells expressing homomeric Slick channels by $\sim 50 \%$. We have now tested the actions of an activator of protein kinase $\mathrm{C}$ [phorbol 12-myristate 13-acetate (PMA)] on the characteristic of the het- eromeric Slick/Slack-B channels and compared them with those of homomeric Slick and Slack-B currents expressed in Xenopus oocytes. Strikingly, application of 100 nM PMA to oocytes coexpressing Slick and Slack-B subunits resulted in a $>90 \%$ suppression of current, a result that cannot be explained by the response to PMA of any linear combination of Slick or Slack-B currents (Fig. 6). This result also supports the hypothesis that the major current in Slick and Slack-B cRNA-coinjected oocytes represents heteromeric Slick/Slack-B channels and that these channels are even more potently regulated by $\mathrm{PKC}$ activation than are the homomeric channels.

The Slack-A subunit does not interact with the Slick subunit There are two major isoforms of the Slack channel that differ only in their extended cytoplasmic $\mathrm{N}$ termini (Brown et al., 2008). All of the experiments described above tested the interaction of Slack-B, the first Slack channel to be described (Joiner et al., 1998; Bhattacharjee et al., 2002; Yuan et al., 2003) with Slick subunits. The cytoplasmic N-terminal regions of Slack-B and Slick are quite distinct, whereas the shorter $\mathrm{N}$ terminus of Slack-A is almost identical with that of Slick. The kinetic properties of Slack-A resemble those of Slick channel, which activates rapidly in response to depolarization. To determine whether Slack-A, like Slack-B, enhances functional expression in the plasma membrane, we injected 
A

Slick-EE/Slack-A
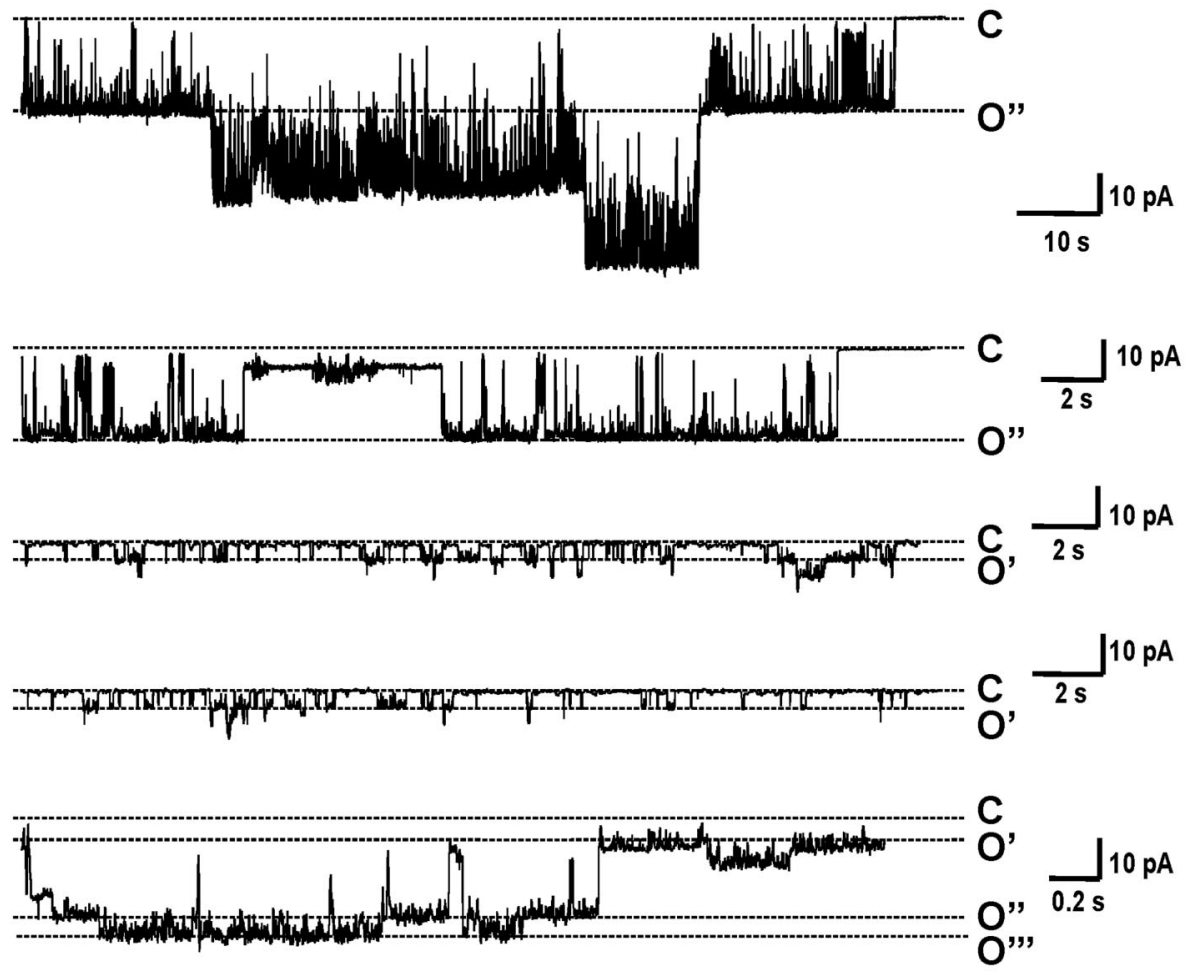

B

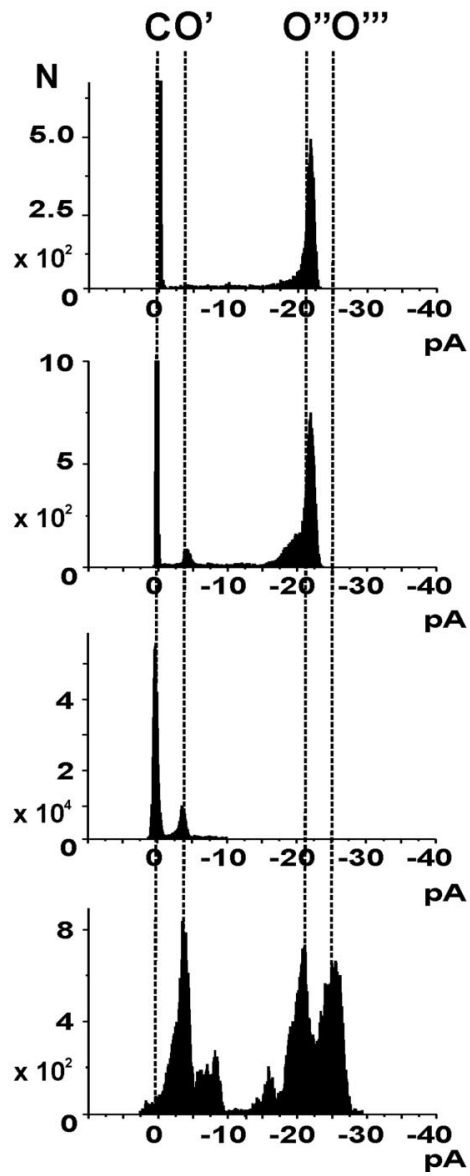

Figure 8. Coexpression of Slick-EE and Slack-A subunits do not generate channels of intermediate unitary conductance. Recordings were performed as described in Figure 4. A, Representative single-channel activities from oocytes coinjected with equal amounts of cRNA for Slick-EE and Slack A. There are two major unitary currents. The larger unitary current matches Slick-EE homomeric channels (top, the first and second traces), whereas the smaller one is consistent with Slack-A homomeric channels (the third and fourth traces). B, Four all-points amplitude histograms are shown for different recordings of patches. The vertical lines align closed states $(C)$ and the predicted opening for single open states of Slack-A channels $\left(0^{\prime}\right)$, single Slick-EE channels $\left(0^{\prime \prime}\right)$, or simultaneous openings of a Slack-A channel and a Slick-EE channel ( $\left.0^{\prime \prime \prime}\right)$.

oocytes with cRNAs for Slick and Slack-A, singly and in combination. Unlike coexpression of Slick and Slack-B, coexpression of Slick and Slack-A did not increase whole-oocyte currents, compared with expression of either subunit alone, and currents in Slick/Slack-Acoinjected oocytes were smaller than those obtained with expression of Slack-A alone (Fig. $7 A, B$ ).

We also monitored the level of surface expression of Slick and Slack-A subunits in Xenopus oocytes using fluorescently tagged channel subunits. We made an additional fusion construct, Slack-A-GFP, which introduced GFP into the C terminus of the Slack-A. In contrast to Slick-DsRed/Slack-B-GFP coinjection experiments (Fig. 2), levels of surface fluorescence for Slack-A-GFP or Slick-DsRed were not enhanced in oocytes coinjected with both constructs over those injected with cRNAs for either subunit alone (Fig. 7C). These experiments indicate that, in contrast to Slack-B, Slack-A subunits fail to enhance trafficking of Slick subunits to the plasma membrane, or their stability in this membrane. This is consistent with the hypothesis that Slick does not form heteromeric channels with Slack-A.

Single-channel recordings also indicate that, in contrast to Slack-B, coexpression of Slack-A subunits with Slick-EE does not generate channels of intermediate unitary conductance. When ooctyes were coinjected with cRNA for Slick-EE and Slack-A in a 1:1 ratio, the size of unitary openings observed in cell-attached and excised inside-out patch recordings was consistent with that of openings of homomeric Slick-EE ( $\sim 495$ pS) or Slack-A channels $(\sim 180 \mathrm{pS})$ or a combination of these conductances (Fig. 8). In no experiments $(N=11)$ were discrete openings corresponding to conductances of $\sim 325 \mathrm{pS}$ observed, as was the case with Slack-B/Slick-coexpressing oocytes.

The N-terminal domain of Slack-B enhances the localization of heteromeric channels to the plasma membrane

As described above, the N-terminal domain of Slack-B is necessary for formation of heteromeric Slick/Slack-B channels. We further investigated whether it also contributes to the enhanced level of functional expression of the heteromeric channel complexes. To test this hypothesis, a chimeric channel was created by replacing the cytoplasmic N-terminal domain of Slick with that of Slack-B, and expressed in Xenopus oocytes (Fig. 9). Compared with expression levels of Slick wild type alone, injection of the same amount of cRNA for this chimera increased the wholeoocyte current at $+60 \mathrm{mV}$ by sixfold, whereas coexpression of the chimera with wild-type Slick subunits induced a 30-fold increase in whole-oocyte currents (Fig. 9). As discussed previously for coexpression of Slack-B with Slick (Fig. 1), because Slick and Slack channels have similar $\mathrm{Na}^{+}$sensitivities, it is unlikely that changes in open probability or $\mathrm{Na}^{+}$sensitivity could increase 
whole-oocyte currents to this degree for coexpression of the chimera with Slick channels. Moreover, because the pore region of the chimeric Slick/wild-type Slick heteromeric channels is identical with that of wild-type Slick channels, changes in single-channel conductance are unlikely to contribute to the 30 -fold increase in current. These results indicate, therefore, that that the Slack-B N-terminal domain plays a key role in trafficking and/or the level of plasma membrane expression of these $K_{\mathrm{Na}}$ channels.

\section{Slick and Slack-B subunits colocalize in neurons}

Previous immunocytochemical work using antibodies against either Slick or Slack-B subunits has shown that both of these subunits are expressed in many neurons of rat brain including those of the olfactory bulb, thalamus, red nucleus, oculomotor nucleus, and the medial nucleus of the trapezoid body (MNTB) in the auditory brainstem (Bhattacharjee et al., 2002, 2005; Bhattacharjee and Kaczmarek, 2005). We have now confirmed such colocalization of Slick and Slack subunits in adult rat brain by double immunocytochemical staining using a chicken anti-Slick antibody and a mouse anti-Slack antibody. Figure 10 shows colocalization of Slick and Slack subunits in two brain regions that have previously been shown to express high levels of these subunits, the MNTB (Fig. $10 \mathrm{~A}$ ) and the oculomotor nucleus (Fig. $10 \mathrm{~B}$ ). In the MNTB, $K_{\mathrm{Na}}$ channels have been characterized and found to contribute to the accuracy of timing of neuronal action potentials (Yang et al., 2007). In sharp contrast, whereas both subunits are expressed in neurons of the CA1 hippocampal region, little or no colocalization of Slick and Slack could be detected in this region (Fig. 10C). Interestingly, both Slick and Slack subunits have been found to be coexpressed in cultured primary hippocampal neurons (data not shown) (Santi et al., 2006), suggesting that the expression of Slick and Slack is developmentally regulated, as has been found for $K_{\mathrm{Na}}$ channels in other tissues (Zhou et al., 2004).

\section{Slick forms heteromeric protein complexes with Slack-B but not Slack-A}

Finally, we performed coimmunoprecipitation experiments to determine whether the Slick subunit binds to Slack-B subunits in rat brain tissue. For this purpose, we prepared a high-affinity Slack-B column by linking chicken anti-Slack-B antibodies (Bhattacharjee et al., 2002) to agarose beads. Using membrane preparations from adult rat brainstems and olfactory bulbs, in which Slick and Slack-B channels are expressed at high levels (Bhattacharjee et al., 2002, 2005), we found that Slick subunits were readily coimmunoprecipitated with Slack-B (Fig. 11A).

We also tested the association of Slick with both Slack-B and Slack-A subunits in transfected HEK293 cells expressing both subunits. For these experiments, we made two fusion constructs, DsRed-Slick and Slack-B-Flag, by inserting a DsRed and a Flag tag into the $\mathrm{N}$ terminus of Slick and the $\mathrm{C}$ terminus of Slack-B, respectively. Then these two constructs were stably cotransfected into HEK 293 cells. The expression of Slick subunits could readily
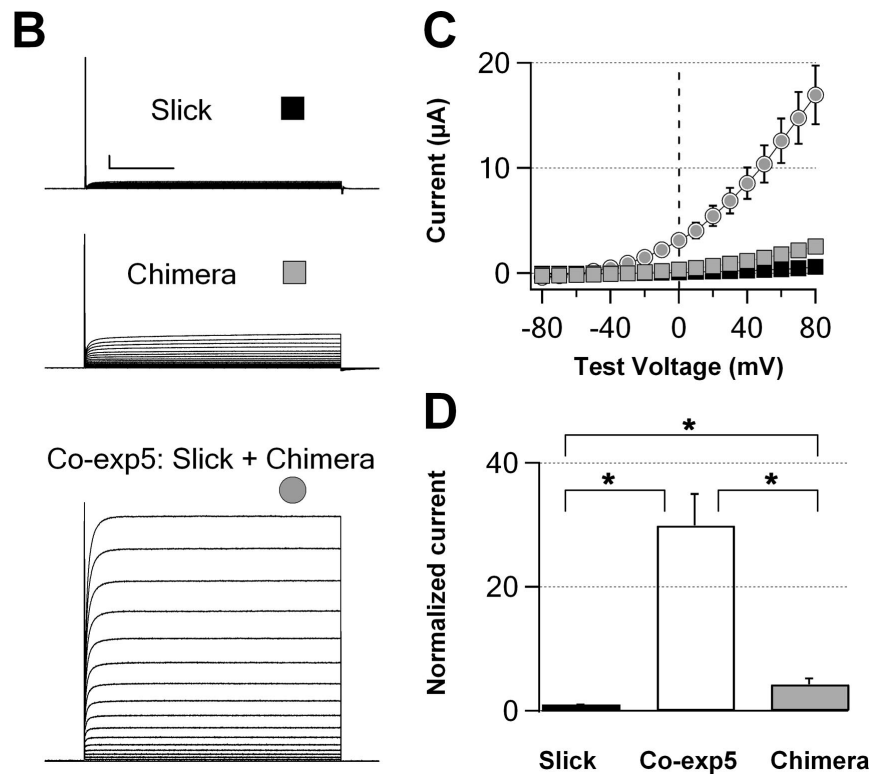

Figure 9. The Slack-B N terminus increases the functional expression of homomeric and heteromeric Slick channels. $A$, Diagrams of Slick, Slack-B, and chimeric (Slack-B-N terminus-Slick channels) subunits. $\boldsymbol{B}$, Representative families of whole-0ocyte Calibration: $1 \mu \mathrm{A}, 100 \mathrm{~ms}$. D, Relative currents at $+60 \mathrm{mV}$ for $\boldsymbol{C}$. Currents are normalized to the mean level of wild-type Slick currents. ${ }^{*} p<0.001$. Error bars indicate SEM.

be monitored by its red fluorescent signal. We immunoprecipitated channel complexes from membrane preparations of the cotransfected cells using a high-affinity anti-Flag antibody against Slack-B-Flag. We found that, as in rat brain, Slick subunits coimmunoprecipitated with Slack-B (Fig. $11 \mathrm{~B}$, lanes 1 and 3 ). When the anti-Flag antibodies were preabsorbed with Flag peptides, we found no detectable immunoprecipitation of either Slack-B or Slick subunits (Fig. $11 B$, lanes 2 and 4). As an additional control, when we immunoprecipitated Slack-B from cells expressing Slack-B-Flag alone, we found no detectable Slick signal in the immunoprecipitate (Fig. $11 B$, lanes 5 and 6).

As described previously, the enhancement of current that occurs with coexpression of Slick with Slack subunits is specific to the Slack-B isoform and does not occur with Slack-A. Because the only difference between Slack-A and Slack-B is in their N termini, and the $\mathrm{N}$ terminus of Slack-A is almost identical with that of Slick, it has not yet been possible to generate an antibody specific to Slack-A. The use of transfected HEK cells therefore allowed us to test the association of Slack-A with Slick subunits. We introduced an HA tag into the C terminus of Slack-A (Slack-A-HA) and stably coexpressed this construct with DsRed-Slick in HEK293 cells. After immunoprecipitation of channel complexes containing Slack-A-HA subunits using high-affinity anti-HA beads, we could detect no DsRed-Slick immunoreactivity in the immunoprecipitate (Fig. 11C, lane 2). In contrast, in the positive control experiment using HEK293 cells stably expressing DsRedSlick alone, we detected a clear Slick band using the same polyclonal anti-DsRed antibody (Fig. 11C, lane 3). These findings support the hypothesis that heteromer formation between Slick and Slack subunits is restricted to the Slack-B isoform.

The experiments in this section detected the presence of Slick subunits by Western blotting in Slack-B immunoprecipitates. We were not able to perform the converse experiment of immunoprecipitating Slick channels and testing for the presence Slack-B 
Chicken anti-Slick
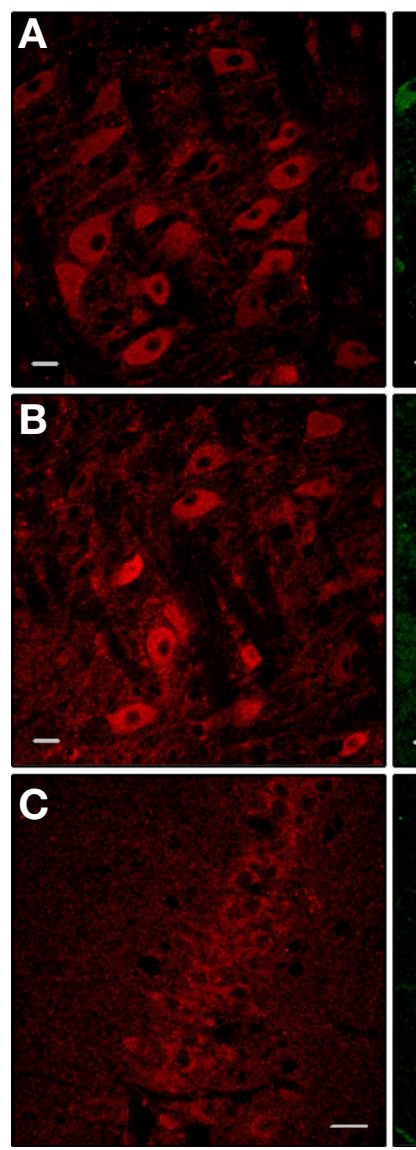

Mouse anti-Slack
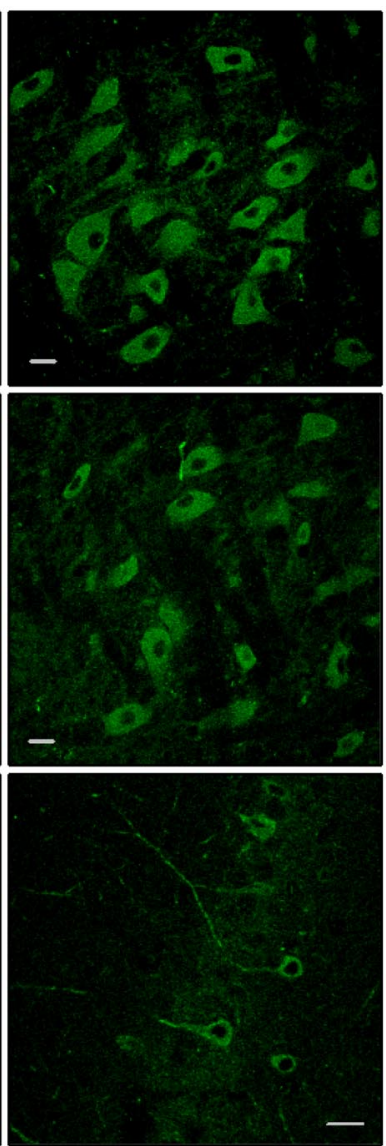

Merged

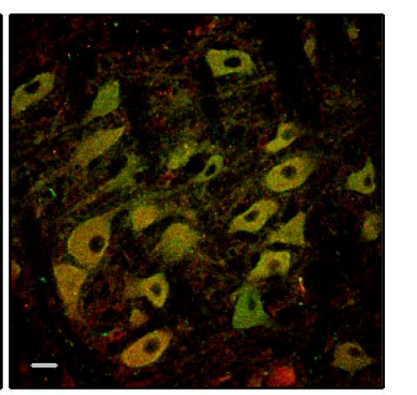

Figure 10. Immunocytochemical colabeling of Slick and Slack subunits in brain sections of adult rat: medial nucleus of the trapezoid body $(\boldsymbol{A})$; oculomotor nuclei $(\boldsymbol{B})$; hippocampal CA1 region $(\boldsymbol{C})$. In control experiments, the omission of primary or secondary antibodies resulted in complete loss of specific labeling (data not shown). Scale bars: $A, B, 20 \mu \mathrm{m} ; C, 50 \mu \mathrm{m}$.

subunits. A number of lines of evidence indicate that this is because neither the chicken anti-Slick antibody against the part of C-terminal domain of Slick (Bhattacharjee et al., 2002) nor antibodies against the epitope tags in the $\mathrm{N}$ or $\mathrm{C}$ terminus of Slick are effective in immunoprecipitating the Slick protein in its nondenatured form, although both of these antibodies detect Slick in denaturing gels.

\section{Discussion}

Previous studies with single-channel recording in cardiac cells and neurons have indicated a diversity of channel behaviors for $K_{\mathrm{Na}}$ channels (Dryer, 2003; Bhattacharjee and Kaczmarek, 2005). Recent work has cloned and characterized two distinct genes, Slick and Slack, that encode $K_{\mathrm{Na}}$ channels (Joiner et al., 1998; Bhattacharjee et al., 2003; Yuan et al., 2003). In this study, we have provided several lines of evidence to support the hypothesis that Slick and Slack-B form heteromeric channel complexes in neurons and that such heteromeric channels may represent one native form of $K_{\mathrm{Na}}$ channel found in neurons. First, coexpression of Slick and Slack-B subunits in Xenopus oocytes produce novel functional channels, which differ from either Slick or Slack-B channels in their trafficking, activation kinetics, single-channel conductance, regulation by $\mathrm{PKC}$, and sensitivity to an intracellular factor that results in rundown after patch excision. Second, Slick and Slack subunits are coexpressed in the same cellular locations in many types of neurons such as those in the oculomo-

tor nucleus and the MNTB. In addition, when expressed in Xenopus oocytes, Slick and Slack-B subunits have the same polarized distributions in the plasma membrane. Finally, we have been able to coimmunoprecipitate Slick subunits with Slack-B subunits from both rat brain tissues and HEK293 cells stably expressing both Slick and Slack-B subunits.

In the heterologous expression system, heteromeric Slick/Slack-B channels exhibit several properties that are distinct from those of homomeric Slick or Slack-B channels. Particularly striking is the finding that heteromeric Slick/Slack-B channels are regulated by protein kinase $\mathrm{C}$ in a manner quite different from that of homomeric Slick or Slack channels. Activation of protein kinase $\mathrm{C}$ produces a much more profound suppression of heteromeric Slick/Slack-B channels than of homomeric Slick channels, whereas PKC increases currents of homomeric Slack-B channels. Neurotransmitters acting through G-protein-coupled receptor pathways are known to modulate neuronal excitability by regulating potassium channels (Cooper and Jan, 2003; Mao et al., 2004). We recently found that neurotransmitters that act through G-protein-coupled receptors to stimulate protein kinase $\mathrm{C}$ activity also regulate homomeric Slick or Slack-B channels (Santi et al., 2006). Our present findings suggest that heteromeric Slick/ Slack-B channels are likely to be much more sensitive to activation of these pathways than are the homomeric channels.

We also found that heteromeric Slick/ Slack-B channels are more sensitive to an as-yet-uncharacterized intracellular factor that results in the rundown of activity after patch excision. Similar rundown of activity after excision has been reported for $K_{\mathrm{Na}}$ channels in olfactory neurons (Egan et al., 1992a), which express high levels of both Slick and Slack subunits (Bhattacharjee et al., 2002, 2005). Work with olfactory neurons indicates that this factor is not related to nucleotide levels or of a number of known second messenger/protein kinase pathways (Egan et al., 1992a). Interestingly, the degree of sensitivity to excision may be cell type specific (Koh et al., 1994; Niu and Meech, 2000) and could reflect the presence of homomeric or heteromeric $K_{\mathrm{Na}}$ channels.

Direct evidence for heteromer formation between Slick and Slack-B was obtained by comparing the unitary conductance of Slack channels, those of a Slick mutant with a very large unitary conductance and heteromers of these two subunits. The large unitary conductance of all BK-type channels has been attributed to the presence of two rings of negative charge in the cytoplasmic inner helix (vestibule) of S6 (Brelidze et al., 2003; Nimigean et al., 2003). Introducing one such ring of four glutamate charges into the KcsA channel produces a fourfold increase in unitary conductance. We therefore used this strategy for the Slick channel by creating the double mutant Slick-EE (Q276E, Y279E). In contrast to wild-type Slick channels, which have a unitary conductance of $140 \mathrm{pS}$, the single-channel conductance of Slick-EE is $\sim 495 \mathrm{pS}$. It 
A Rat Brain

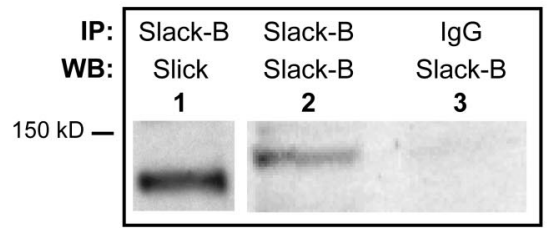

B HEK 293

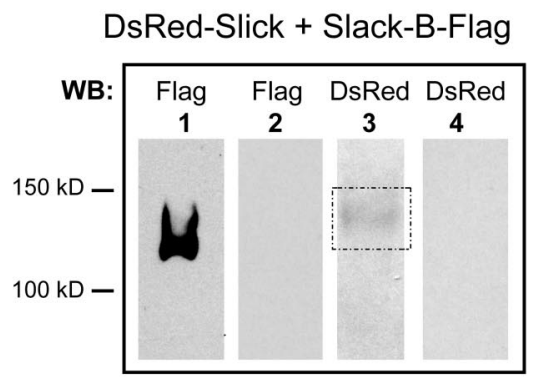

Slack-B-Flag alone

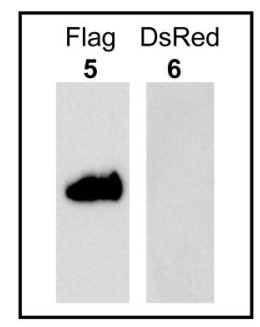

C HEK 293

DsRed-Slick + Slack-A-HA

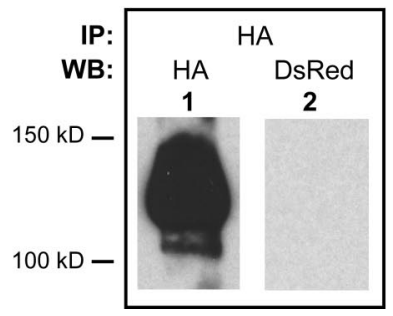

DsRed-Slick alone

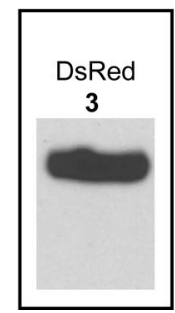

Figure 11. Coimmunoprecipitation of Slick and Slack subunits in rat brain and transfected cells. A, A clear Slick band was detected in immunoprecipitated proteins from brainstems and olfactory bulbs using chicken anti-Slack-B antibodies (lane 1). Control experiments demonstrated that the anti-Slack-B antibody-linked beads immunoprecipitated Slack-B subunits (lane 2) but that no signal was detected in immunoprecipitations with control lgG antibodies (lane 3). $\boldsymbol{B}$, Slick subunits were coimmunoprecipitated with Slack-B subunits from HEK293 cells stably cotransfected with both subunits. A weak Slick band at $140 \mathrm{kDa}$ was detected with polyclonal anti-DsRed antibody (box in lane 3), whereas a strong Slack-B signal at $126 \mathrm{kDa}$ was detected with anti-Flag M2 antibody (lane 1) in the same blotting membrane after treatment with stripping buffer (Pierce). Lanes 2 and 4, Negative controls with addition of Flag peptides. Lanes 5 and 6, Another negative control from HEK293 cells stably expressing Slack-B-Flag alone. C, Slick subunits did not coimmunoprecipitate with Slack-A subunits. Anti-HA beads were used to immunoprecipitate channels or channel complexes from HEK293 cells, which were stably transfected with Slack-A-HA and DsRed-Slick fusion constructs. No Slick signal was detected (lane 2), although there was a very strong Slack-A signal (lane 1). Lane 3 shows a positive control for Slick subunits from HEK293 cells stably expressing DsRed-Slick alone.

is reasonable to assume that the presence of additional negative charge in the Slick channel, at positions 275 and 283, compared with BK channels, may explain this very large conductance of Slick-EE channels.

If coexpressed Slick-EE and Slack-B subunits were to associate randomly in the plasma membrane, one would expect to observe a binomial distribution of unitary conductances (Zheng and Sigworth, 1998), with values corresponding to those of Slack-B alone, Slick-EE alone, and to those of heteromers with either 1:3 or 2:2 ratios of the two subunits. We did not observe this. Although we very occasionally detected channels corresponding to Slick-EE or Slack-B alone, we detected predominantly one major conductance with a value intermediate between that of Slack-B and Slick-EE. The most obvious reason for this is that these two subunits do not associate randomly because the heteromeric channels are selectively targeted or stabilized in the plasma membrane. Thus, the intermediate conductance that we observe in patches clearly represents the heteromeric channels, but we cannot make any definitive statements about the stoichiometry of this heteromer.

In addition to effects on unitary conductance and sensitivity to protein kinase $\mathrm{C}$ activation, the coexpression of Slick and Slack-B in heterologous systems results in greatly enhanced expression of the heteromeric Slick/Slack-B channels in the plasma membrane. If similar regulation of localization occurs in native neurons, then such heteromeric channels are likely to dominate in neurons in which both subunits are expressed. The altered pattern of subcellular distribution of the subunits in HEK cells expressing both subunits, compared with cells expressing each subunit alone is consistent with a selective increase in the surface trafficking of the heteromeric channels to the plasma membrane. It is also possible, however, that the stabilization of the heteromeric channel in the plasma membrane and/or a decrease in internalization also contributes to the greatly increased levels of channels in the plasma membrane. Interestingly, the enhancement of trafficking of Slick-containing channels and the formation of heteromers appears to be specific to the Slack-B isoform. Recent work has identified two different splice variants of the Slack gene, Slack-A and Slack-B (Brown et al., 2008). Expression of these two variants is regulated by different promoters and they differ in sequence only at the $\mathrm{N}$-terminal presumed cytoplasmic domains. The $\mathrm{N}$ terminus of Slack-A is almost identical with the $\mathrm{N}$ terminus of Slick and is much shorter than of Slack-B. By both electrophysiological and coimmunoprecipitation criteria, Slick does not appear to form channel complexes with Slack-A and we have demonstrated directly that the Slack-B N-terminal domain is required for the interaction between the two subunits. In particular, enhanced trafficking of Slick channels to the plasma membrane can be observed in a chimeric channel in which the $\mathrm{N}$-terminal domain of Slack-B has been grafted onto the Slick subunits.

Intracellular N-terminal domains have been found to play key roles in formation and/or trafficking of other heteromeric potassium channel complexes such as $\mathrm{KChiP} / \mathrm{Kv} 4$, MinK/KCNQ1, eag, and $\beta 1 / \mathrm{Kv} 1$ channels (Gulbis et al., 2000; Callsen et al., 2005; Wang et al., 2007; Phartiyal et al., 2008). There are several possibilities for the functional role of the Slack-B $\mathrm{N}$ terminus. It may contain a functional motif similar to the T1 domain of voltagegated Shaker-family potassium channels, which is a key determinant for forming heteromultimeric channels (Zerangue et al., 2000). Alternatively, the Slick $N$ terminus may contain potential endoplasmic reticulum retention motifs, which are missing in the Slack-B N terminus, and association of the subunits may mask these motifs, resulting in more efficient trafficking to the plasma membrane, a mechanism demonstrated for SUR/Kir6.2 potassium channels (Tucker et al., 1997; Zerangue et al., 1999). Finally, there may exist other intracellular accessory subunits, which specifically interact with the Slack-B N-terminal domains and increase the trafficking and functional expression of the chimera channel, comparable with mechanisms described for KChip/Kv4 potassium channel complexes (Bähring et al., 2001).

\section{References}

Bader CR, Bernheim L, Bertrand D (1985) Sodium-activated potassium current in cultured avian neurones. Nature 317:540-542.

Bähring R, Dannenberg J, Peters HC, Leicher T, Pongs O, Isbrandt D (2001) 
Conserved Kv4 N-terminal domain critical for effects of $\mathrm{Kv}$ channelinteracting protein 2.2 on channel expression and gating. J Biol Chem 276:23888-23894.

Bhattacharjee A, Kaczmarek LK (2005) For $\mathrm{K}^{+}$channels, $\mathrm{Na}^{+}$is the new $\mathrm{Ca}^{2+}$. Trends Neurosci 28:422-428.

Bhattacharjee A, Gan L, Kaczmarek LK (2002) Localization of the Slack potassium channel in the rat central nervous system. J Comp Neurol 454:241-254.

Bhattacharjee A, Joiner WJ, Wu M, Yang Y, Sigworth FJ, Kaczmarek LK (2003) Slick (Slo2.1), a rapidly-gating sodium-activated potassium channel inhibited by ATP. J Neurosci 23:11681-11691.

Bhattacharjee A, von Hehn CA, Mei X, Kaczmarek LK (2005) Localization of the $\mathrm{Na}^{+}$-activated $\mathrm{K}^{+}$channel Slick in the rat central nervous system. J Comp Neurol 484:80-92.

Bischoff U, Vogel W, Safronov BV (1998) $\mathrm{Na}^{+}$-activated $\mathrm{K}^{+}$channels in small dorsal root ganglion neurones of rat. J Physiol 510:743-754.

Brelidze TI, Niu X, Magleby KL (2003) A ring of eight conserved negatively charged amino acids doubles the conductance of BK channels and prevents inward rectification. Proc Natl Acad Sci U S A 100:9017-9022.

Brown MR, Kronengold J, Gazula VR, Spilianakis CG, Flavell RA, von Hehn CA, Bhattacharjee A, Kaczmarek LK (2008) Amino-termini isoforms of the Slack $\mathrm{K}^{+}$channel, regulated by alternative promoters, differentially modulate rhythmic firing and adaptation. J Physiol 586:5161-5179.

Callsen B, Isbrandt D, Sauter K, Hartmann LS, Pongs O, Bähring R (2005) Contribution of $\mathrm{N}$ - and C-terminal Kv4.2 channel domains to KChIP interaction [corrected]. J Physiol 568:397-412.

Cooper EC, Jan LY (2003) M-channels: neurological diseases, neuromodulation, and drug development. Arch Neurol 60:496-500.

Dryer SE (2003) Molecular identification of the $\mathrm{Na}^{+}$-activated $\mathrm{K}^{+}$channel. Neuron 37:727-728.

Dryer SE, Fujii JT, Martin AR (1989) A Na $^{+}$-activated $\mathrm{K}^{+}$current in cultured brain stem neurones from chicks. J Physiol 410:283-296.

Egan TM, Dagan D, Kupper J, Levitan IB (1992a) Properties and rundown of sodium-activated potassium channels in rat olfactory bulb neurons. J Neurosci 12:1964-1976.

Egan TM, Dagan D, Kupper J, Levitan IB (1992b) $\mathrm{Na}^{+}$-activated $\mathrm{K}^{+}$channels are widely distributed in rat CNS and in Xenopus oocytes. Brain Res 584:319-321.

Gulbis JM, Zhou M, Mann S, MacKinnon R (2000) Structure of the cytoplasmic beta subunit-T1 assembly of voltage-dependent $\mathrm{K}^{+}$channels. Science 289:123-127.

Haimann C, Magistretti J, Pozzi B (1992) Sodium-activated potassium current in sensory neurons: a comparison of cell-attached and cell-free single-channel activities. Pflugers Arch 422:287-294.

Hess D, Nanou E, El Manira A (2007) Characterization of $\mathrm{Na}^{+}$-activated $\mathrm{K}^{+}$currents in larval lamprey spinal cord neurons. J Neurophysiol 97:3484-3493.

Hofherr A, Fakler B, Klöcker N (2005) Selective Golgi export of Kir2.1 controls the stoichiometry of functional Kir2.x channel heteromers. J Cell Sci 118:1935-1943.

Joiner WJ, Tang MD, Wang LY, Dworetzky SI, Boissard CG, Gan L, Gribkoff VK, Kaczmarek LK (1998) Formation of intermediate-conductance calcium-activated potassium channels by interaction of Slack and Slo subunits. Nat Neurosci 1:462-469.

Kameyama M, Kakei M, Sato R, Shibasaki T, Matsuda H, Irisawa H (1984) Intracellular $\mathrm{Na}^{+}$activates a $\mathrm{K}^{+}$channel in mammalian cardiac cells. Nature 309:354-356.

Kim YC, Sim JH, Kang TM, Suzuki H, Kim SR, Kwon SC, Xu WX, Lee SJ, Kim KW (2007) Sodium-activated potassium current in guinea pig gastric myocytes. J Korean Med Sci 22:57-62.

Koh DS, Jonas P, Vogel W (1994) $\mathrm{Na}^{+}$-activated $\mathrm{K}^{+}$channels localized in the nodal region of myelinated axons of Xenopus. J Physiol 479:183-197.

Mao J, Wang X, Chen F, Wang R, Rojas A, Shi Y, Piao H, Jiang C (2004)
Molecular basis for the inhibition of $G$ protein-coupled inward rectifier $\mathrm{K}^{+}$channels by protein kinase C. Proc Natl Acad Sci USA 101:1087-1092.

Nimigean CM, Chappie JS, Miller C (2003) Electrostatic tuning of ion conductance in potassium channels. Biochemistry 42:9263-9268.

Niu XW, Meech RW (2000) Potassium inhibition of sodium-activated potassium $\left(K_{\mathrm{Na}}\right)$ channels in guinea-pig ventricular myocytes. J Physio 526:81-90.

Paulais M, Lachheb S, Teulon J (2006) $\mathrm{A} \mathrm{Na}^{+}$- and $\mathrm{Cl}^{-}$-activated $\mathrm{K}^{+}$channel in the thick ascending limb of mouse kidney. J Gen Physiol 127:205-215.

Pessia M, Tucker SJ, Lee K, Bond CT, Adelman JP (1996) Subunit positional effects revealed by novel heteromeric inwardly rectifying $\mathrm{K}^{+}$channels. EMBO J 15:2980-2987.

Phartiyal P, Sale H, Jones EM, Robertson GA (2008) Endoplasmic reticulum retention and rescue by heteromeric assembly regulate human ERG 1a/1b surface channel composition. J Biol Chem 283:3702-3707.

Rajan S, Plant LD, Rabin ML, Butler MH, Goldstein SA (2005) Sumoylation silences the plasma membrane leak $\mathrm{K}^{+}$channel K2P1. Cell 121:37-47.

Rodrigo GC, Chapman RA (1990) A sodium-activated potassium current in intact ventricular myocytes isolated from the guinea-pig heart. Exp Physiol 75:839-842.

Safronov BV, Vogel W (1996) Properties and functions of $\mathrm{Na}^{+}$-activated $\mathrm{K}^{+}$channels in the soma of rat motoneurones. J Physiol 497:727-734.

Santi CM, Ferreira G, Yang B, Gazula VR, Butler A, Wei A, Kaczmarek LK, Salkoff L (2006) Opposite regulation of Slick and Slack $\mathrm{K}^{+}$channels by neuromodulators. J Neurosci 26:5059-5068.

Schwake M, Pusch M, Kharkovets T, Jentsch TJ (2000) Surface expression and single channel properties of KCNQ2/KCNQ3, M-type $\mathrm{K}^{+}$channels involved in epilepsy. J Biol Chem 275:13343-13348.

Tucker SJ, Gribble FM, Zhao C, Trapp S, Ashcroft FM (1997) Truncation of Kir6.2 produces ATP-sensitive $\mathrm{K}^{+}$channels in the absence of the sulphonylurea receptor. Nature 387:179-183.

Wang H, Yan Y, Liu Q, Huang Y, Shen Y, Chen L, Chen Y, Yang Q, Hao Q, Wang K, Chai J (2007) Structural basis for modulation of Kv4 K ${ }^{+}$channels by auxiliary KChIP subunits. Nat Neurosci 10:32-39.

Wang HS, Pan Z, Shi W, Brown BS, Wymore RS, Cohen IS, Dixon JE, McKinnon D (1998) KCNQ2 and KCNQ3 potassium channel subunits: molecular correlates of the M-channel. Science 282:1890-1893.

Wang Z, Kimitsuki T, Noma A (1991) Conductance properties of the $\mathrm{Na}^{+}$. activated $\mathrm{K}^{+}$channel in guinea-pig ventricular cells. J Physiol 433:241-257.

Yang B, Desai R, Kaczmarek LK (2007) Slack and Slick $K_{\mathrm{Na}}$ channels regulate the accuracy of timing of auditory neurons. J Neurosci 27:2617-2627.

Yuan A, Santi CM, Wei A, Wang ZW, Pollak K, Nonet M, Kaczmarek L, Crowder CM, Salkoff L (2003) The sodium-activated potassium channel is encoded by a member of the Slo gene family. Neuron 37:765-773.

Zerangue N, Schwappach B, Jan YN, Jan LY (1999) A new ER trafficking signal regulates the subunit stoichiometry of plasma membrane $\mathrm{K}(\mathrm{ATP})$ channels. Neuron 22:537-548.

Zerangue N, Jan YN, Jan LY (2000) An artificial tetramerization domain restores efficient assembly of functional Shaker channels lacking T1. Proc Natl Acad Sci U S A 97:3591-3595.

Zhang Y, Paterson WG (2007) Functional evidence for $\mathrm{Na}+$-activated $\mathrm{K}^{+}$ channels in circular smooth muscle of the opossum lower esophageal sphincter. Am J Physiol Gastrointest Liver Physiol 292:G1600-G1606.

Zheng J, Sigworth FJ (1998) Intermediate conductances during deactivation of heteromultimeric Shaker potassium channels. J Gen Physiol 112:457-474

Zhou M, Liu Z, Hu C, Zhang Z, Mei Y (2004) Developmental regulation of a $\mathrm{Na}^{+}$-activated fast outward $\mathrm{K}^{+}$current in rat myoblasts. Cell Physiol Biochem 14:225-230. 